\title{
Review Article \\ Carbon Nanotube and Graphene Based Polyamide Electrospun Nanocomposites: A Review
}

\author{
Fabiola Navarro-Pardo, ${ }^{1,2}$ Ana L. Martinez-Hernandez, ${ }^{1}$ and Carlos Velasco-Santos ${ }^{1}$ \\ ${ }^{1}$ División de Estudios de Posgrado e Investigación, Instituto Tecnológico de Querétaro, 76000 Santiago de Querétaro, QRO, Mexico \\ ${ }^{2}$ Centre Énergie Matériaux Télécommunications, Institut National de la Recherche Scientifique, Varennes, QC, Canada J3X 1S2
}

Correspondence should be addressed to Carlos Velasco-Santos; cylaura@gmail.com

Received 26 February 2016; Accepted 4 May 2016

Academic Editor: Niranjan Patra

Copyright (C) 2016 Fabiola Navarro-Pardo et al. This is an open access article distributed under the Creative Commons Attribution License, which permits unrestricted use, distribution, and reproduction in any medium, provided the original work is properly cited.

\begin{abstract}
Electrospinning is a unique and versatile technique to produce nanofibres; the facility to incorporate fillers has expanded its range of applications. This review gives a brief description of the process and the different polymers employed for obtaining nanofibres. Owing to the ability of fibrillation of polyamides, these polymers have resulted in a wide variety of interesting results obtained when using this technique; therefore these features are summarised. Additionally, because of the feasibility of incorporating carbon nanotubes and graphene in these nanofibres and the growing interest on these nanomaterials, this review focuses in the most common methods employed for their incorporation in electrospun polyamides. Several equipment setups used for the electrospinning of the nanofibres are explained. The outstanding electrical, optical, crystallinity, and mechanical properties obtained by a number of research groups are discussed. The potential applications of the resulting nanocomposites have also been explored.
\end{abstract}

\section{Introduction}

Electrospinning is a unique technique that can effectively produce fibres with diameters ranging from micrometers to several nanometres using a wide variety of materials [1-4]. This approach has been known since its patent was issued in 1924 by Formhals; however it was not until the last couple of decades that there was a revival on the interest of applying such technique in order to produce nanofibres. In this regard, Reneker and Chun promoted the interest of electrospinning and they have also provided a detailed review about the mechanism of electrospinning process including a diversity of polymers that were electrospun in their laboratory [1]. Teo and Ramakrishna have also offered a review on this process about different materials that have been electrospun, such as polymers, composites, ceramics, and metals [3]. Electrospinning of polymers has been very attractive because of the interesting characteristics when the diameters of the fibres are in the nanoscale [1-7].

Luo et al. reviewed the different insights found between the academia and the industry about the nanofibre research, providing also a comprehensive comparison of the conventional techniques for obtaining fibres [7]. Nanofibres are exceptional when compared to any other fibres due to the very large surface area to volume ratio (which can be as large as $10^{3}$ times compared to a microfibre) which leads superior mechanical performance (e.g., stiffness and tensile strength), high porosity, high gas permeability, and small interfibrous pore size [5-16]. Some authors have reviewed a variety of electrospun nanofibres and highlighted their potential for their use in filtration membranes, $[5,6]$, solar cells $[6,8]$, electronic devices [8], and biomedical applications $[9,17,18]$.

A number of polymers such as polyacrylonitrile [10], polyvinyl acetate [11], polyvinylidene fluoride/polypyrrole [12], poly-E-caprolactone [13], polystyrene [14], polyethylene [15], and natural-synthetic hybrids like chitosan/starch/ polyethylene terephthalate [16] have been used to obtain electrospun fibres. Huang and coworkers have made an extensive review of the processing parameters, features, modelling, and simulations related to a variety of polymers that have been electrospun into nanofibres [2]. Polyamides are suitable for electrospinning processing due to their polyelectrolytic 
behaviour in acid solution [19]. They are among the most used polymers for the successful electrospinning due to their mechanical properties, such as high tensile and impact strength, durability, and chemical and abrasion resistance $[5,19]$. The outstanding properties of the nanofibres have attracted a lot of attention from many research groups due to the high production rate and the facility to incorporate reinforcing materials expanding the range of applications that can be obtained through this process.

Nanomaterials can impart remarkable structural and physical properties to the matrix as reinforcement agents [20-22]. Among the fillers used to reinforce nanofibres are metal nanoparticles [23-25], nanoclays [26-28], and carbon nanomaterials [29-38]. CNTs have been studied in the last two decades and since the raising of graphene a lot of research has been focused on these two carbon allotropes in polymer nanocomposites $[21,29,30]$. CNTs are known to possess high aspect ratio, elastic modulus values of $\sim 1 \mathrm{TPa}$, and tensile strength of $60-150 \mathrm{GPa}[21,29]$. They have been observed to have thermal conductivity as high as $6000 \mathrm{~W} / \mathrm{cmK}$ and electrical conductivity of $5000 \mathrm{~S} / \mathrm{cm}$ [29]. The tensile strength of graphene is similar or slightly higher than CNTs (130 GPa); although CNTs show comparable mechanical properties to graphene, this $2 \mathrm{D}$ carbon filler has superior properties than those of the $1 \mathrm{D}$ carbon filler in certain aspects, such as thermal and electrical conductivity [30]. Because of their high strength and high aspect ratio carbon based nanocomposite fibres with extraordinary superior mechanical properties have been obtained $[20,31,32]$. Electrical $[33,34]$ and physical $[35,36]$ properties have also been enhanced by the incorporation of these nanomaterials. Yeo and Friend have reviewed several aspects of CNT based electrospun nanofibres [20]. However, there are no reviews on graphene based nanocomposites obtained from electrospinning.

This review focuses on CNT and graphene based polyamide nanofibres because of the above mentioned characteristics that carbon nanofillers can provide and the wide use of this polymer in electrospinning. In addition, it is important to highlight the different properties that can be obtained in the nanofibres taking into account different aspects for the processing of these carbon based nanocomposites. In this regard, we have summarised the different methods and setups used for the nanocomposite preparation and the effects provided in the morphological, optical, electrical, crystallisation, and mechanical properties of nanocomposite electrospun fibres. The prospective applications of these nanofibres are also presented.

\section{Nanocomposite Preparation}

Electrospun fibres are obtained from a polymer solution; when nanofillers are incorporated, they have to be dispersed in the liquid medium by vigorous stirring and/or sonication followed by the mixing of the dispersion with a polymer solution [29]. Pristine nanometric carbon is extremely difficult to disperse and align in a polymer matrix because it usually forms strong bundles due to van der Waals forces between adjacent carbon nanomaterials $[37,38]$. Furthermore, CNTs and graphene have an atomically smooth nonreactive surface; the lack of interfacial bonding inhibits load transfer from the matrix to nanomaterial across the nanomaterial/polymer interface [64]. Therefore, the main challenges for obtaining carbon based nanocomposites with remarkable properties are the improvement of the dispersion, alignment, and interfacial adhesion of nanometric carbon within the matrix. Many works have been directed to overcome these shortcomings in carbon based nanocomposites [25, 37, 38, 64-69].

Electrospinning is an ideal route for aligning carbon nanomaterials $[2,65]$; the different approaches and results obtained by several groups will be discussed in the next section. Functionalisation provides efficient stress transfer from the polymer matrix to the nanometric carbon by preventing aggregation of them, providing a better dispersion of the nanomaterials in the polymer matrix $[37,66,67]$. It also increases the polymer-nanomaterial physical contact and can form chemical bonds between the nanomaterial and the polymer matrix [66]. The functional groups at the surface of nanometric carbon make the strongest type of interfacial bonding with the polar polymer matrices [64]. Selected functional groups can broaden the properties of the carbon nanomaterials through the formation of donoracceptor complexes with the graphitic structure, affording the tunability of electrical conductivity and optical properties [68]. Moreover, the additional organic moieties on the surface of carbon nanomaterial can improve the solubility of them to suit different solvents $[68,69]$.

Polyamides consist of methylene segments $\left(\mathrm{CH}_{2}\right)_{n}$ separated by amide units (NH-CO). The presence of the polar groups makes functionalisation of carbon nanofillers a relevant approach for the preparation of electrospun fibres. Table 1 shows the different carbon nanomaterials used in polyamide electrospun fibres. According to the works summarised, the most commonly employed carbon nanofillers are those characterised by having oxygenated groups in their structure. Pristine carbon nanotubes typically contain carbonaceous impurities and metal catalyst particles [21,29]. Purification of CNTs is typically achieved by oxidation using strong acids $[21,29,66]$. This process originates functional groups such as carbonyl, hydroxyl, and carboxyl on the graphitic surface [21, 69]. An extensively used strategy for obtaining graphene is the modification of graphite through oxidative routes for its subsequent exfoliation to produce GO [38]. The carboxylic acid groups at the sheet edges and epoxy and hydroxyl groups on the basal plane of GO sheets allow them to disperse in polar solvents [64]. Amino functionalised CNTs and graphene have also been incorporated into electrospun nanocomposites [31, 32, 44, 45, 70]. Jeong et al. showed that amino functionalised CNTs have better stability during the same period of time when compared to acid treated nanotubes; see Figure $1[34,45]$. Our research group studied the influence of the dimensionality of both $1 \mathrm{D}$ and 2D carbon fillers on the dispersion of PA66; the capability of the CNTs to bend and the higher amount of $\mathrm{NH}_{2}$ on their surface when compared to graphene sheets allowed the $1 \mathrm{D}$ nanotubes to interact with each other resulting in aggregation of them when incorporated into the polymer matrix [31]. Avila-Vega et al. incorporated nitroxide groups to GO using 
TABLE 1: Polyamide electrospun nanofibres reinforced with 1D and 2D carbon.

\begin{tabular}{|c|c|c|c|c|}
\hline Nanofiller & Functionalising agents & Polymer matrix & Solvent & Reference \\
\hline P-MWCNTs & - & PA66 & FA & {$[32]$} \\
\hline O-MWCNTs & $\mathrm{H}_{2} \mathrm{SO}_{4} / \mathrm{HNO}_{3}$ & PA66 & FA & {$[32]$} \\
\hline A-MWCNTs & EDAC/DMA & PA66 & FA & {$[31]$} \\
\hline O-MWCNTs & Not specified & PA66 & $\mathrm{FA} / \mathrm{DCM}$ & {$[35,39]$} \\
\hline O-SWCNTs & $\mathrm{H}_{2} \mathrm{SO}_{4} / \mathrm{HNO}_{3}$ & PA6 & FA & {$[40]$} \\
\hline P-MWCNTs & - & PA6 & FA & {$[41]$} \\
\hline P-CNTs & - & PA6 & HFIP & {$[42]$} \\
\hline MWCNTs-OH & $\begin{array}{l}\mathrm{KMnO}_{4} \text { in the presence of a phase transfer } \\
\text { catalyst/dispersed in DMF }\end{array}$ & PA66 & FA & {$[43]$} \\
\hline O-MWCNTs & $\mathrm{HNO}_{3} / \mathrm{HCl}$ dispersed in DMF & PA11 & $\mathrm{FA} / \mathrm{DCM}$ & {$[44]$} \\
\hline A-MWCNTs & $\mathrm{SOCl}_{2} / \mathrm{EDA}$ & PA66 & FA & {$[34,45]$} \\
\hline O-MWCNTs & $\mathrm{H}_{2} \mathrm{SO}_{4} / \mathrm{HNO}_{3}$ & PA6 & HFIP & {$[46]$} \\
\hline O-MWCNTs & $\mathrm{HNO}_{3} / \mathrm{HCl}$ dispersed in Triton X-100 & PA610 & HFIP & [47] \\
\hline O-MWCNTs & $\begin{array}{c}\mathrm{HNO}_{3} / \mathrm{HCl} \text { dispersed in DMF or Triton X-100 and } \\
\text { sodium dodecyl sulfate }\end{array}$ & PA66 & FA & {$[48]$} \\
\hline P-MWCNTs & Dispersed in Triton X-100 & PA6 & HFIP & [49] \\
\hline A-MWCNTs & $\mathrm{SOCl}_{2} / \mathrm{EDA}$ & PA6 & FA & {$[50]$} \\
\hline P-MWCNTs & - & PA6 & FA & {$[50]$} \\
\hline O-MWCNTs & $\mathrm{H}_{2} \mathrm{SO}_{4} / \mathrm{HNO}_{3}$ & PA6 & FA & {$[51]$} \\
\hline Ac-MWCNTs & Friedel-Crafts acylation & PA6 & FA & {$[52]$} \\
\hline P-MWCNTs & - & PA6 & FA & {$[52]$} \\
\hline O-MWCNTs & Commercially obtained & PA6 & HFIP & {$[53]$} \\
\hline O-MWCNTs & Commercially obtained & PA6 & Cresol/FA & [54] \\
\hline RGO & Hydrazine & PA66 & FA & {$[55]$} \\
\hline NGO & Oxoammonium salts & PA6 & HFIP & {$[41,56]$} \\
\hline RGO & Hydrazine & PA66 & $\mathrm{FA} / \mathrm{DCM}$ & {$[33,57]$} \\
\hline RGO & Hydrazine & PA66 & FA & {$[57]$} \\
\hline GnPs & Commercially obtained & PA6 & HFIP & [58] \\
\hline $\mathrm{GO}$ & Hummers method & PA66 & FA & [32] \\
\hline $\mathrm{AGe}$ & EDAC/DMA & PA66 & FA & {$[31]$} \\
\hline RGO & Hexamethylentetramine & PA66 & FA & {$[32]$} \\
\hline $\mathrm{TiO}_{2}-\mathrm{RGO}$ & Hydrothermal method & PA6 & FA/AA & {$[59]$} \\
\hline RGO & Hydrothermal method & PA6 & $\mathrm{FA} / \mathrm{AA}$ & {$[60]$} \\
\hline GO & Hummers and Offeman's method & PA6 & FA & {$[61]$} \\
\hline RGO & Hydroiodic acid & PA6 & FA & {$[62]$} \\
\hline BSA-GO & Electrostatic self-assembly & PA6 & FA & {$[63]$} \\
\hline
\end{tabular}

a new method for functionalising and exfoliating GO sheets in one step [41]. Table 1 also shows that other authors have employed techniques taking advantage of Van der Waals, $\pi$ $\pi$, CH- $\pi$, and other interactions; the adsorbed surfactants, biomolecules, or polymers provide repulsive and attractive forces creating stable dispersions [47-49, 63].

A large number of investigations have employed a nanofiller dispersion followed by mixing with the polyamide solution [31-36, 39, 41, 42, 45, 50, 51, 55, 56, 58-60, 71-73]. Table 1 also shows that PA6 and PA66 are the most studied polymers and the solvents used for the electrospinning of the nanofibres are also included. Kim et al. reported that the ultrasonication of O-MWCNTs in DMF provides a dispersion of individual nanotubes which is stable and can be stored at room temperature for several months without precipitation [48]. According to Lala and coworkers, HFIP is the best solvent for dispersing P-MWCNTs effectively when compared to different solvents [49]. FA has also been used for dispersing CNTs and graphene in polyamides [31, 32, 55]. This organic solvent offers fine dispersion stability of the carbon nanomaterials and good solubility of polyamides $[34,45]$. A combination of this solvent with others such as DCM and AA has also been used [33, 35, 39].

Another approach employed for obtaining these nanocomposites is by dip-coating the nanofibres previously obtained by electrospinning in a carbon nanomaterial 


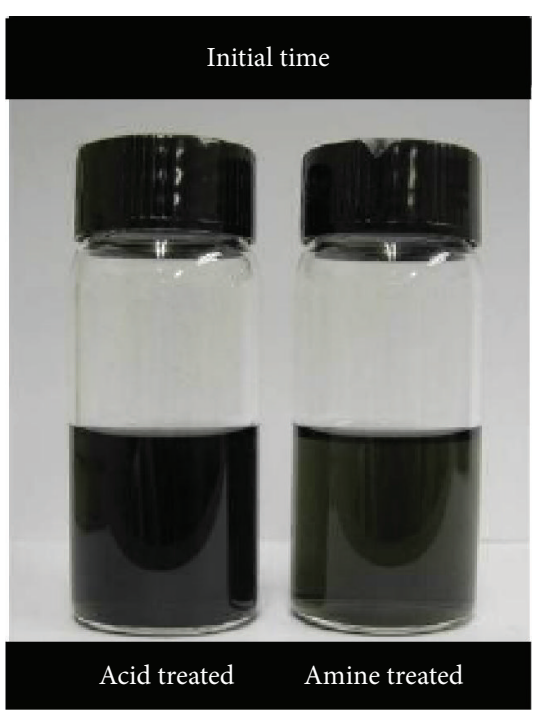

(a)

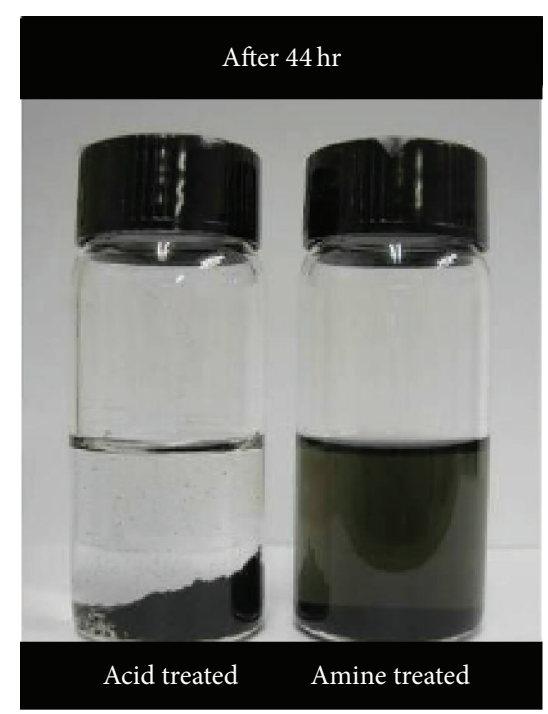

(b)

FIGURE 1: Images of the MWCNTs dispersed in a formic acid solution (sonication 30 min). (a) Initial status and (b) after 44 h. Reprinted from [45], Copyright 2006, with permission from Elsevier.

dispersion $[33,40,43,48,49,57,74,75]$. In this method, the nanometric carbon is adsorbed onto the surface of nanofibre mats as shown in Figure 2. Kim et al. studied the effect of two surfactants on the adsorption of O-MWCNTs; the nonionic surfactant resulted in a higher degree of adsorption of the nanotubes on the PA66 nanofibres [48]. This method is useful for obtaining transparent films [40]. Havel et al. adapted a similar method to deposit O-MWCNTs onto nanofibre mats allowing the formation of a thin conductive 2D network [44].

PVP was used to act as a modifier for improving the adsorption of GO sheets onto the nanofibres via strong $\pi$ $\pi$ interactions; the additional sites on the PVP-GO surface provided hydrogen bonding with neighbouring PA66 nanofibres; this route was also used for the reduction of GO by a combination of hydrazine vapour treatment and thermal annealing $\left(350^{\circ} \mathrm{C}\right)$ [33]. Pant et al. employed hydrothermal treatment for the reduction of GO in PA6 nanofibres [60]. In addition, another work of these authors showed that these RGO/P6 fibres facilitated the deposition of $\mathrm{TiO}_{2}$ nanoparticles either on the nanonets or on the graphene sheets present on the main nanofibres [59]. Other authors have adsorbed GO onto the nanofibres followed by the reduction of the graphene sheets $[33,55,57,61]$. Figure 3 shows a method for fabricating yarns from PA6 electrospun fibres functionalised with BSA molecules (yellow dots, Figure 3(a)). The GO was wrapped via electrostatic self-assembly with BSA (Figure 3(b)), which served as an adhesive for improving the adsorption of GO sheets onto the textile, followed by a lowtemperature chemical reduction of GO (Figure 3(c)) [62, 63]. Cruz-Silva et al. developed a new technique for obtaining electrospun PA fibres on top of freestanding GO film [76]. Wang et al. penetrated RGO nanosheets of different sizes onto PA66 nanofibres for constructing smooth conductive paths within polymer nanofibre fabrics [77].
An in situ polymerisation technique has also been used to prepare MWCNT/PA6 nanocomposites with subsequent electrospinning [52], showing better dispersion of the nanotubes when functionalised with amino groups. Kang and Jin also used a similar approach in order to incorporate OMWCNTs into PA610 [47].

The type of method used for the incorporation of the carbon nanofiller in a matrix will have a repercussion in the application to which they will be destined. A good dispersion of the carbon filler inside the polymer is required for those applications where strength is needed $[4,17,18,78-82]$. Thin, transparent, conducting films are critical for their use as electrodes in modern electronic devices [8, 22, 40, 57, 77]. For chemical sensors the interactions of the analyte with the carbon nanomaterials have suggested a better performance when they are surface adsorbed using a surfactant $[49,74,75]$.

\section{Morphology of the Electrospun Fibres}

Electrospinning provides electrostatic stretching forces (whipping elongation) for overcoming any entanglement of nanomaterials [70]. A uniform distribution of carbon nanomaterials is critical for preventing nanofiller protrusion, notches, and beads across the fibre body $[56,70]$. Polymer solution properties, such as molecular weight, solution viscosity, surface tension, solution conductivity, and dielectric constant, are critical factors that affect the electrospun fibre morphology $[68,83,84]$. Process parameters, such as applied voltage, polymer flow rate, and capillary-collector distance, also have diverse effects on the morphological appearance and average fibre diameter [14, 17, 35, 71, 84].

Different electrospinning setups have been made to control the alignment of the polyamide electrospun fibres $[2,17$, 71]; among the different approaches developed are rotating 

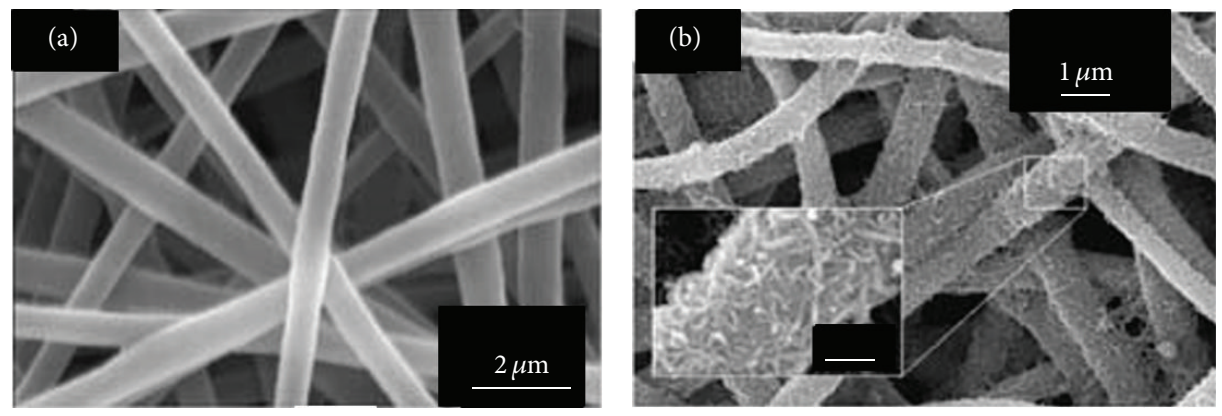

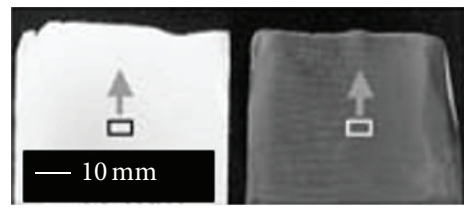

(c)

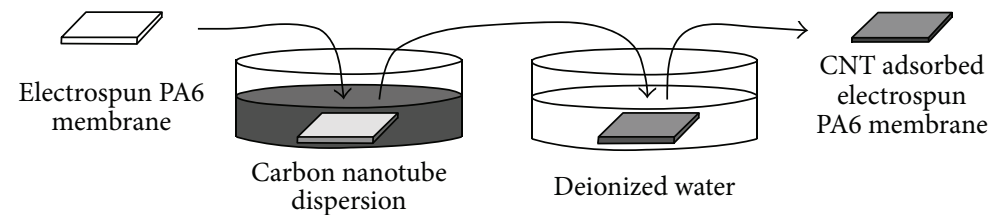

(d)

FIGURE 2: High-resolution SEM images of the nonwoven fibrous PA6 membranes (a) before and (b) after dip-coating in a dispersion of O-MWCNTs in water (0.05 wt.\%) containing Triton X-100 surfactant (0.3 wt.\%). (c) Images of nonwoven fibrous PA6 and the O-MWCNTadsorbed nonwoven fibrous PA6 and (d) scheme of the simple processing technique used for producing the O-MWCNT-adsorbed nonwoven fibrous PA6 membranes. Reprinted from [48], Copyright 2005, with permission from John Wiley and Sons.

(i)

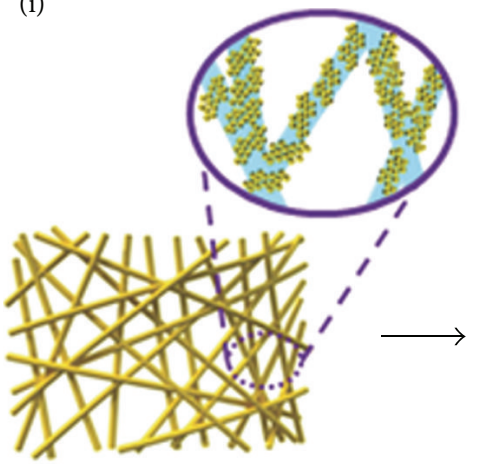

BSA-coated fibre

(a) (ii)

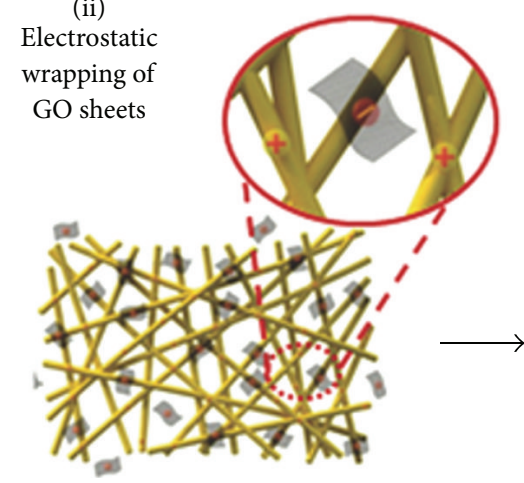

GO fibre

(b)

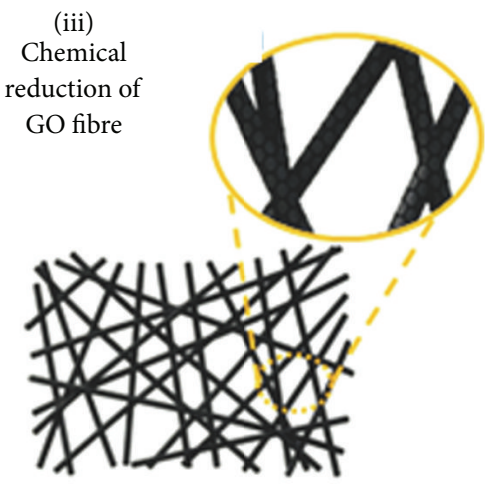

RGO fibre

(c)

Figure 3: Schematic illustration of the three steps used to prepare RGO nanoyarns. Reprinted from [63], Copyright 2005, with permission from John Wiley and Sons.

drums [14, 34, 45], parallel plates [39], rotating discs [70], electrically rotating viscoelastic jets [10], grounded collector plates $[31,32,55]$, and self-blending coelectrospinning [58, 85]. Applying other stretching forces can also enhance the alignment of the nanofillers along the fibre axis [70] and this is also a promising way to improve the molecular orientation degree in the fibre [70]. Parallel plates enabled the collection of aligned PA66 fibre arrays [39]. Aligned fibre bundles can also be obtained by a phase-inversion method. In this method the fibres are collected on a water bath; once they are floating on water they are transferred to a rotating drum and aligned in bundles of $\sim 20 \mu \mathrm{m}$ in diameter $[6,51]$. Liu et al. obtained individual fibres of PA6/MWCNTs with diameters ranging from 200 to $300 \mathrm{~nm}$ using this technique [51]. This method has been used to fabricate microfiltration and ultrafiltration membranes $[59,70]$. Moreover the manipulation of geometrical stretching of the electrospun nanofibres can favour the alignment of nanomaterials in the polymer matrix [70]. Highspeed rotating collectors have also been used to collect and to align CNTs in the polymer matrix. A study showed that the mechanical properties are affected by the alignment of PA6 fibres and the enhanced orientation of MWCNTs by the take-up speed [46]. The alignment of fibres is important for engineering the nanostructure and it also provides the ability to twist the aligned fibre bundles for fabricating nanoyarns $[63,71]$. Yarns of twisted electrospun MWCNT/PA6 composite nanofibres, ranging from 5 to $10 \mu \mathrm{m}$ in diameter, have been produced by a two-disk mechanism where a first disk 

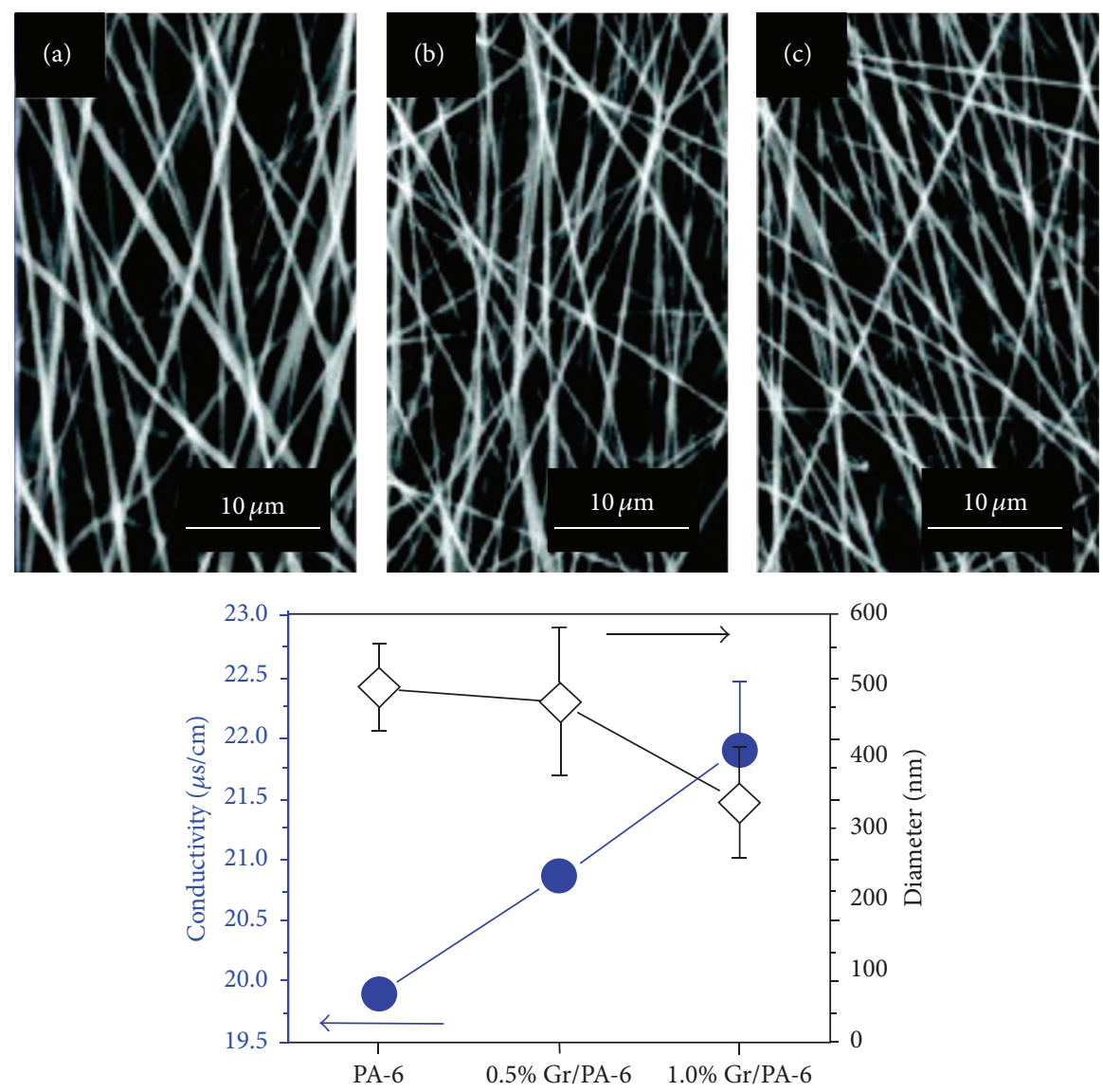

(d)

Figure 4: SEM images of as-spun (a) PA6 nanofibres, (b) 0.5\% GnP/PA6 nanofibres, and (c) 1.0\% GnP/PA-6 nanofibres. (d) Plot on the correlations of fibre diameters (black hollow diamond) and electrical conductivity (blue solid circle) versus PA6 solutions containing varied amount of GnP nanosheets. Reprinted from [58], Copyright 2013, with permission from Elsevier.

with controlled rotation imparts twist to a fibre bundle and then this is continuously wound on by a second disk with a constant linear speed [70].

The electrospinning setups have an influence on the morphology of the fibres; however, the content of the nanomaterials also affects the diameter of the nanofibres. These nanofillers produce changes in the physical properties of the solutions such as viscosity and electrical conductivity. Increasing the content of the carbon nanofiller provides a higher viscosity which in turn will produce thicker fibres. On the other hand, the electrical conductivity will also be higher and will favour the stretching of thinner fibres [32]. Due to these opposite behaviours some studies have shown variable fibre diameters as the loading of the nanofiller is increased $[32,46,50,51]$. Li et al. obtained PA6 nanofibres with decreasing diameter as the loading of GnPs was increased. Figure 4 shows that GnPs gave rise to the electrical conductivity and produced finer nanofibres [58]. There are other works that have shown the reduced diameter of the nanofibres as the nanofiller loading increased $[42,55]$. Addition of LA to PA6 for obtaining electrospun fibres produced nanofibres with flat and ribbon-shaped morphologies with wrinkled surfaces when compared to the cylindrical pure PA6 nanofibres.
Furthermore, incorporation of CNTs decreased the fibre diameter, attributed to the increased electrical conductivity of the electrospun solutions [42]. Avila-Vega et al. found that the stability of the solutions also lead to effects on the homogeneity of the diameters of NGO/PA6 nanofibres [41]. The diameter of the nanofibres has been found to be related to the mechanical and thermal properties $[35,39]$.

Additionally, in the last decade a variant of the commonly known electrospun nanofibres has been developed; this approach known as electrospinning/netting refers to the formation of nanofibres with diameters below $50 \mathrm{~nm}$ which connect with each other forming a spider-web-like morphology among the main nanofibres of larger diameter. Wang et al. have made a review on the recent advances when achieving this type of morphology, summarising several properties found in these type of bimodal diameter nanofibres [84]. Interestingly, PA6 was the first polymer to show this type of morphology; therefore there is valuable information about the parameters to obtain this interconnecting nets in electrospun polyamides; however, research regarding this type of morphology in nanofibres reinforced with carbon nanomaterials is limited. Pant et al. have reported that the incorporation of GO into PA6 allowed the formation of a 


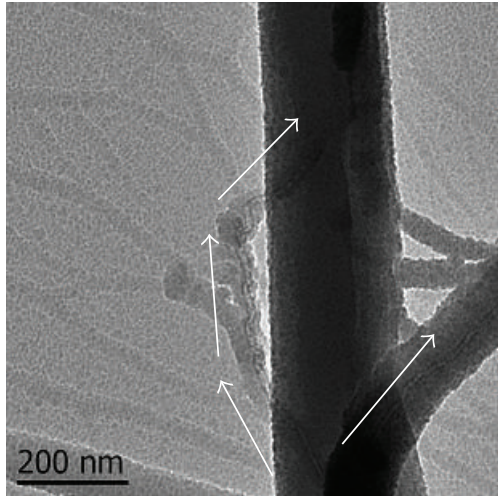

(a)

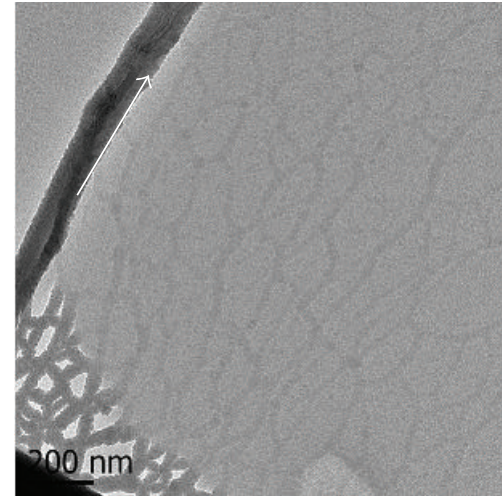

(b)

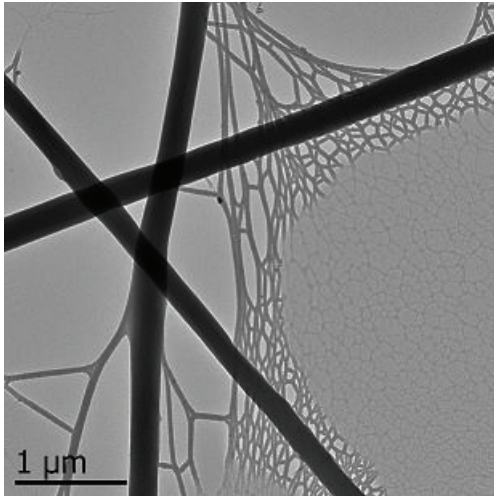

(c)

FIGURE 5: TEM images of $1 \mathrm{wt} . \%$ O-MWCNT/PA66 nanofibres showing (a) O-MWCNT oriented along the small diameter nanofibre, (b) $\mathrm{O}-\mathrm{MWCNT}$ oriented in the large diameter nanofibre, and (c) bimodal diameter nanofibres.

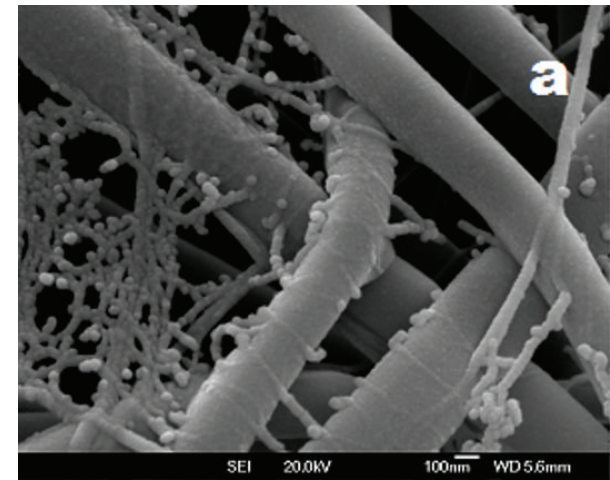

(a)

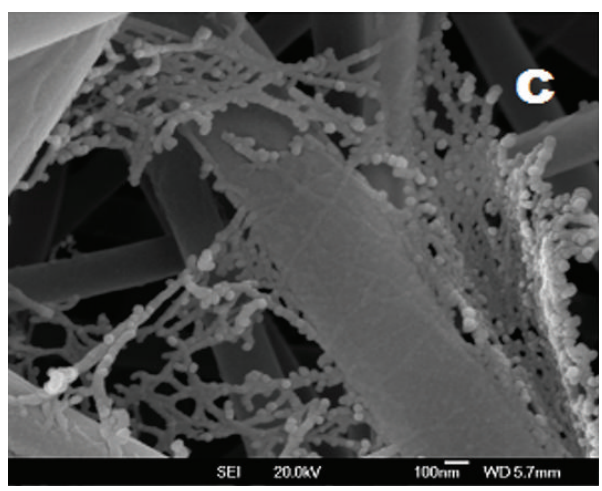

(c)

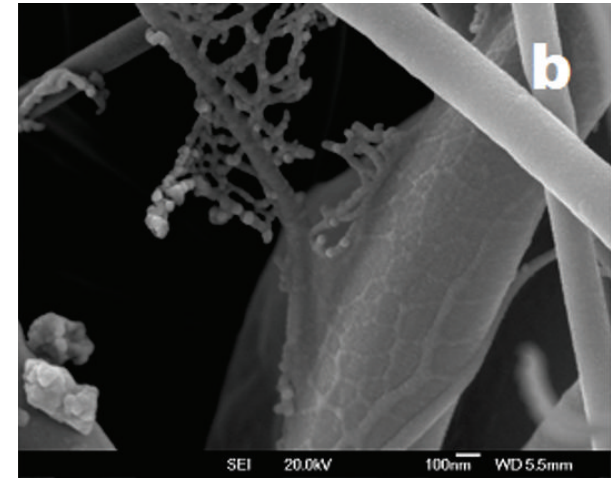

(b)

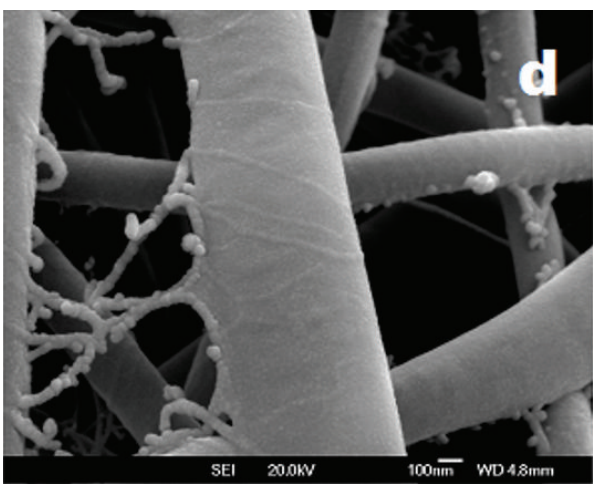

(d)

FIgure 6: SEM images of (a) P-CNT/PA66 nanofibres, (b) A-CNT/PA66, (c) RGO/PA66, and (d) AG/PA66.

large/scale uniform bimodal fibres with distributed thick $(\sim$ $200 \mathrm{~nm})$ and thin $(\sim 13 \mathrm{~nm})$ fibre diameter in spider-wavelike nanonets $[36,60]$. The formation of spider-wave-like nanonets was attributed to the fast solvent degradation of PA6 caused by well dispersed GO sheets through the electrospinning solution [36]. Figure 5 displays TEM images obtained in our research group; the spider-net like structures were also found in PA66 electrospun fibres reinforced with oxidised MWCNTs. Furthermore, Figure 6 shows this type of morphology in PA66 nanofibres containing diverse 1D and $2 \mathrm{D}$ carbon nanomaterials also synthesised in our group, indicating that addition of carbon nanofillers has a favouring effect for the formation of netting among the main PA66 nanofibres. This can be related to the increased conductivity achieved in the solution by the incorporation of nanofillers. Electrospinning conditions can be found in [31,32].

Pant and coworkers have explained that the increased conductivity of different pure PA6 solutions increased the ionization of polymer and therefore the fibres were characterised by these subnanofibres [86]. Furthermore, several 

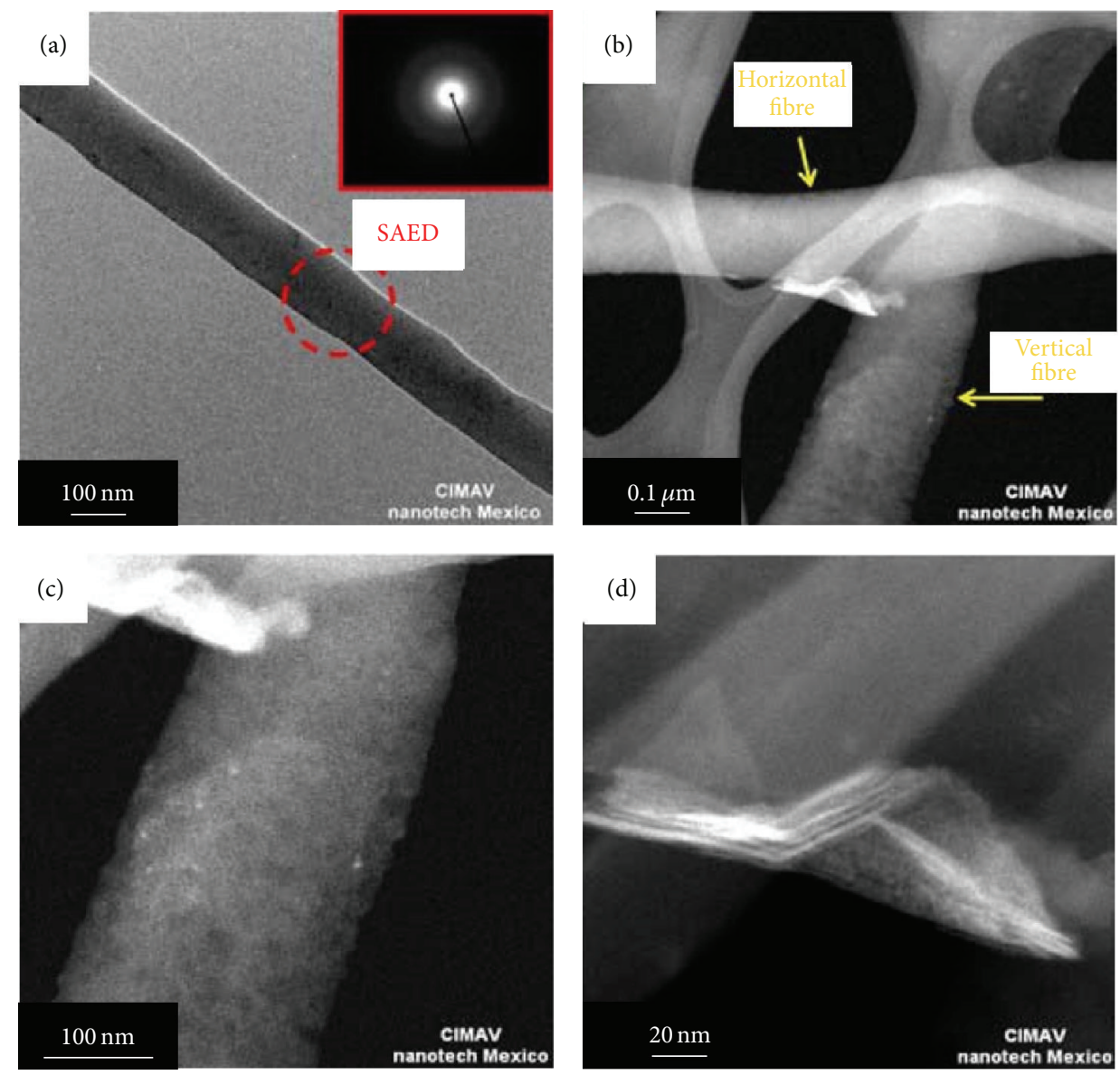

FIGURE 7: (a) TEM bright field image. The inset shows the SAED acquired in the circumscribed region by the red dotted circle. (b) STEM Zcontrast image showing two fibres containing NGO layers. Arrows indicate the horizontal and vertical fibres. Higher magnification Z-contrast images from (c) vertical fibre and (d) horizontal fibre. Reprinted from [56], Copyright 2010, with permission from Elsevier.

authors have found that the electrospinning process usually favours the alignment of CNTs in the nanofibres [31, 32, $53,70]$. This behaviour is due to the converging nanoscale jet reducing the number of available orientations in the flow field [53]. NGO was aligned within the PA6 nanofibres meanwhile agglomerates of the nanofiller could hardly be aligned; therefore the NGO sheets protruded from the fibres; Figure 7 shows the NGO/PA6 nanofibres [56].

Zomer Volpato et al. found that the surface of PA6 electrospun fibres was rough with defects attributed to the fibre stretching and the presence of O-MWCNTs in the nanocomposite fibres resulted in greater surface roughness compared to the control nanofibres [53]. Yun et al. fabricated a RGO/PA6 fabric from randomly oriented nanocomposite fibres with diameters of $150-200 \mathrm{~nm}$; numerous wrinkles were observed by high-resolution SEM, indicating the uniform wrapping of the RGO nanosheets onto PA nanofibres [63]. GnPs/PA6 nanofibres have also been used as reinforcement fillers in simultaneous electrospinning of PMMA [58]. The PMMA fibres were melted in situ to become the matrix, whereas the GnPs/PA6 nanofibres with higher melting point maintained their original morphology within the PMMA matrix; this method was used for achieving a good dispersion by using the graphene based nanofibres as dispersing carriers in the polymer matrix.

\section{Electrical and Optical Properties}

Nanometric carbon based films have attracted a lot of interest because of the outstanding electrical and mechanical properties of CNTs and graphene [40,57, 61]. Using minimal amounts of CNTs or graphene in a polymer makes the resulting nanocomposites electrically conductive. Conductivity of carbon based nanocomposites increases markedly once the nanofiller content becomes high enough to percolate, that is, to form a connected network that acts as a conductive pathway through the nonconductive polymer matrix [33, 34, 43, 49, 69]. In addition, percolation threshold increases significantly when processing methods cause nanofillers to align [69] and also polyamides can offer high transparency depending upon electrospinning parameters [33]. Consequently, electrospinning of polyamides reinforced with carbon nanomaterials offers the possibility to guide the 


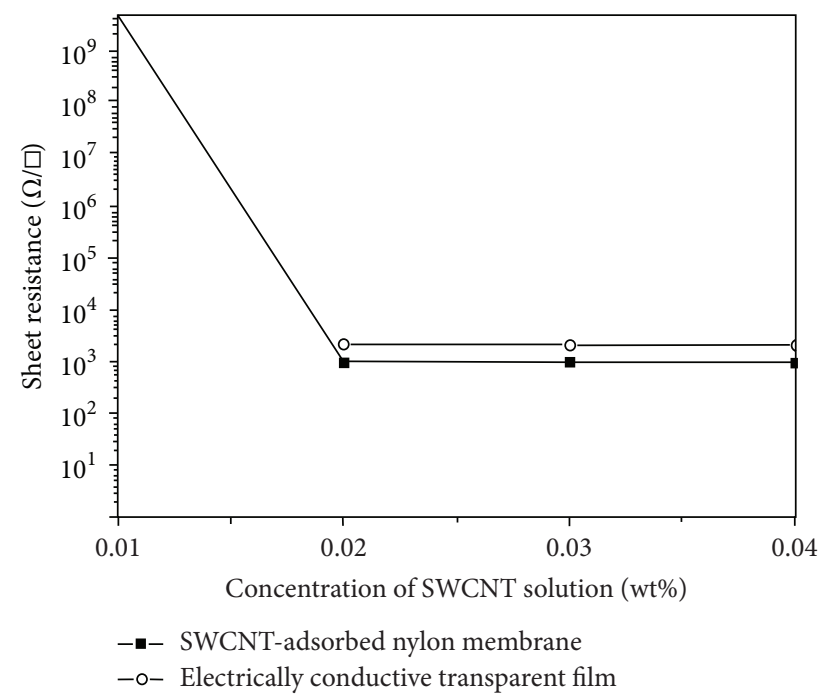

FIGURE 8: Sheet resistances of the O-SWCNT-absorbed PA6 membranes and the electrically conductive transparent films with respect to the O-SWCNT dispersion concentration. Reprinted from [40], Copyright 2013, with permission from Elsevier.

nanofillers adsorbed on the nanofibres in order to obtain thin transparent conducting films [33, 40].

Bak et al. incorporated a transparent epoxy resin into a membrane made from O-SWCNT adsorbed on polyamide nanofibres [40]. Figure 8 shows that a content of $0.02 \mathrm{wt} . \%$ was sufficient for the formation of a percolated network of O-SWCNTs with electrical pathways, resulting in sheet resistance of $950 \mathrm{k} \Omega / \mathrm{sq}$ for the nanofibres and the same behaviour was found in the epoxy resin-impregnated films which achieved higher sheet resistance than the membrane. This film transmitted $77.4 \%$ of the light at $550 \mathrm{~nm}$. Another approach for enhancing the electrical conductivity of MWCNT/PA fibres was developed by Blasdel et al., where PPy was used for interconnecting MWCNT in the fibres; the resulting material acted as a reliable resistance temperature detector in the range of $25^{\circ} \mathrm{C}$ to $45^{\circ} \mathrm{C}$ [75].

Adsorption of O-MWCNTs on PA11 fibres showed the highest coating of CNTs and thinnest electrospun films resulted in the best combination of electrical and optical properties; the results achieved were a sheet resistance of $440 \mathrm{k} \Omega / \mathrm{sq}$ and $95 \%$ transmittance was achieved after melting the polymer nanofibres [44]. These properties were also studied in RGO/PA66 films as a function of electrospinning time. The surface electrical resistivity gradually decreased with increasing density of PA66 nanofibres and the transmittance decreased as the electrospinning time increased [33]. After annealing a film obtained from $120 \mathrm{~s}$ of electrospinning time and immersed in $0.05 \mathrm{wt}$ \% PVP-GO solution exhibited a surface resistance of $8.6 \mathrm{k} \Omega / \mathrm{sq}$ and $88 \%$ light transmittance [33]. Higher loadings of nanofillers have also been used [45, 51]. Liu et al. found that the conductivity of PA6 improved significantly as the loading of MWCNTs was increased up to a 3 wt.\% [51]. Jeong et al. conducted I-V measurements of PA66 nanofibres containing different amounts of MWCNTs; they found that the current increased from $0.59 \mathrm{~mA}$ to $1.77 \mathrm{~mA}$ when the nanofiller loading was increased from $10 \mathrm{wt} \%$ to 20 wt.\% [45]. Nirmala et al. found further increases when adding Ag nanoparticles to MWCNTs/PA6 fibres [87].

Addition of GO or RGO into PA6 nanofibres boosted the electron conduction path. Furthermore the spider-wave structure which was a feature of these nanocomposites allowed the bridging between the PA6 nanofibres and the graphene sheets increasing the amounts of charge carriers and reducing the hopping distance of conduction electrons which favoured the percolation phenomenon [60]. The GO/PA6 nanofibres favoured the electrical conductivity resulting in a three times larger increment on this property than that of the pure PA6 nanofibres; additionally, GO reduction treatment produced an excellent enhancement in this property achieving values 300 times higher than the pure polymer mats [60]. In another work, chemical reduction of GO resulted in an increase of six orders of magnitude in the electrical conductivity when compared to the GO/PA6 nanofibres; this was attributed to the restoration of the conjugated network on the RGO sheets [63]. Wang et al. effectively penetrated RGO into PA66 fibres facilitating the construction of electron pathways within the fabric and promoting electrical conductivity [77].

\section{Crystallinity Properties}

Semicrystalline polymers are sensitive to shear and deformation producing changes in the polymorphism and crystallite orientation [88]. Polyamides are semicrystalline polymers; their molecular structure, morphology, and crystallinity are determined by hydrogen bonded sheets formed between near-neighbour amide groups; and these sheets are stacked together by Van der Waals forces between methylene chains $[5,89]$. Stephens et al. found that electrospinning process modifies the chain conformation of polyamide backbone due to the high stress induced on the jet as the fibres are being formed [90]. Electrospun fibres consist of densely packed aligned lamellae and fibrillar structures. Surrounding the crystalline regions the amorphous phase consists of extended tie molecules [91]. The addition of a second phase is expected to favour crystallisation, reduce crystal size, and therefore impart better mechanical properties to the fibres $[26,31,32$, 35]. However, there is disagreement among diverse studies on carbon nanocomposites as to whether their presence alters the mechanism of crystal growth or the overall degree of crystallinity [69].

Several studies of electrospun CNT/polyamide nanocomposites showed the influence that nanotubes have on crystallisation of the polymer [31, 32, 35, 39, 46, 52, 92]. Jose et al. found that the structure of PA6 transforms from the single $\gamma$ phase for pure polymer to a mixture of $\gamma$ and $\alpha$ phases as the nanotube loading increased. This study also showed that the structure of the nanocomposite and the take-up speed of the obtained fibres were independent when comparing similar loadings of O-MWCNTs [46]. Saeed et al. found that electrospinning of P-MWCNTs and Ac-MWCNTs did not affect the crystal structure of PA6 upon functionalisation of nanotubes. On the other hand, this study showed that 
the shear force during electrospinning might favour the $\gamma$ phase [52]. This phase is often associated with the formation of extended chain crystals and is typically obtained from a process involving elongational flow [88]. The addition of a small amount of O-MWCNTs induced crystallisation in PA66 fibres; however no significant difference in enthalpy values was seen when the loading of O-MWCNTs was higher than 1 wt.\% $[35,39]$. The presence of nanotubes in the fibres leads to smaller but larger number of crystals, explaining the increase of crystallinity in the reinforced fibres [35]. The crystallisation of PA66 electrospun fibres using A-MWCNTs and $\mathrm{AGe}$ as filler has also been investigated in our group. CNTs provided decrease in the crystallinity and higher crystal size when compared to graphene based nanofibres [32]. Lee et al. found that P-MWCNTs influenced the crystallinity degree of PA6 nanofibres [50]. In addition, the two crystalline peaks of PA6 downshifted from the theoretical value; this behaviour was attributed to the close-packing during the electrospinning. Cai and coworkers showed that the addition of LA produced a detriment on the crystallisation of PA6 nanofibres. However, the incorporation of P-CNTs could effectively promote the heterogeneous nucleation in the polymer [42]. Jeon et al. also showed the nucleating behaviour of MWCNTs on electrospun fibres, where pristine MWCNTs started nucleation at higher crystallisation temperatures when compared to O-MWCNTs [92].

The study on the crystallinity properties of graphene based nanofibres obtained from polyamides is limited. Albañil-Sanchez et al. found that increasing the concentration of RGO intensified and narrowed the crystalline reflections of PA66, suggesting the nucleating behaviour of these nanomaterial [55]. Similar results were found in our research group, by adding GO and AGe [31, 32]. Our results showed that an increase in the nanofiller content produced smaller crystal sizes in the nanocomposite fibres. In another experiment, addition of GnPs into PA6 modified the crystalline phase from $\alpha$ to $\gamma$, when compared to the pure polymer; this was attributed to high-speed electrospinning process along with the nucleating behaviour of the nanofiller [58]. Figure 9 shows that the crystal structure of PA transforms from $\gamma$ (Figure 9(a)) to $\alpha$ upon hydrothermal treatment of GO (Figure 9(b)). The diffractogram also shows the presence of the different peaks of the anatase $(A)$ and rutile (R) forms of $\mathrm{TiO}_{2}$ and also both crystalline phases of PA6 [59].

\section{Mechanical Properties}

The alignment of carbon nanofillers by electrospinning enhances the axial mechanical and physical properties of the fibres [65]. Several researchers have reported systematic investigations of the effects of electrospinning parameters on fibre diameter, morphology, and the effect on the mechanical properties [33, 36, 39, 46]. A study using different collector speeds showed the influence on mechanical properties at different loadings of O-MWCNTs in PA6 fibres; the high drawing speed provided a fibre rearrangement at testing direction and therefore better load transfer. Combining high

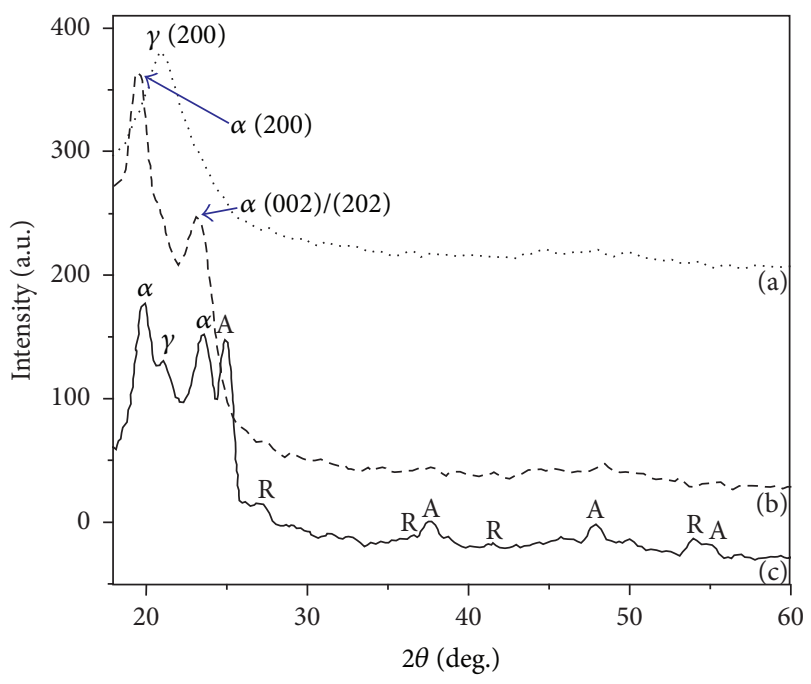

FIGURE 9: XRD patterns of (a) GO/PA6, (b) RGO/PA6, and (c) $\mathrm{TiO}_{2}-\mathrm{RGO} / \mathrm{PA} 6$ mats. Reprinted from [59], Copyright 2007, with permission from Elsevier.

take-up speeds and 1 wt.\% of O-MWCNTs increased the modulus $797 \%$ when compared to pure PA6 fibres, as seen in Figure 10 [46]. Baji et al. studied the influence of diameter on the mechanical properties. The tensile modulus and strength versus O-MWCNT content for each fibre diameter are presented in Figures 11(a) and 11(b), respectively. They concluded that the reinforcement effect of O-MWCNTs is controlled by the fibre diameter. In the fibres with smaller diameter, the size of the surface regions is comparable to the overall fibre diameter, while in the fibres with larger diameter, the surface regions are much smaller compared to the overall fibre diameter. Therefore, fibres of smaller diameter display improved strength and stiffness values [35]. O-MWCNT/PA6 nanofibres showed decreased stiffness when compared to the pure polymer nanofibres; this was attributed to the different architecture of the tested mats [53]. Bazbouz and Stylious found that the tensile test for nonwoven nanofibre mats was not suitable for reflecting the exact mechanical properties of nanofibres. They provided a more accurate characterisation by conducting the tensile tests on single nanofibres or even aligned nanofibre bundles [72].

Functionalisation is also important for the improvement of mechanical properties. Specific tensile strengths of A-MWCNT/PA6 fibres were enhanced from $207 \mathrm{~kg}_{\mathrm{f}} \mathrm{cm} / \mathrm{g}$ for PA6 nanofibres to $389 \mathrm{~kg}_{\mathrm{f}} \mathrm{cm} / \mathrm{g}$ when using $1 \mathrm{wt} . \% \mathrm{~A}-$ MWCNTs. Functionalisation favoured a better dispersion of the nanotubes in the matrix when compared to PMWCNT/PA6 nanofibres which resulted in $359 \mathrm{~kg}_{\mathrm{f}} \mathrm{cm} / \mathrm{g}$ for the same nanotube content [52]. Breaking strain of AMWCNT/PA6 nanofibres was improved due to the interfacial bonding between both phases when compared to the PMWCNT/PA6 nanofibres [50]. Tensile properties of these AMWCNT/PA6 electrospun fibres, including initial modulus, tensile strength, and breaking strain, were improved after applying a thermal posttreatment [50]. Addition of $1 \mathrm{wt}$.\% OMWCNTs to PA66 nanofibres increased the tensile modulus 


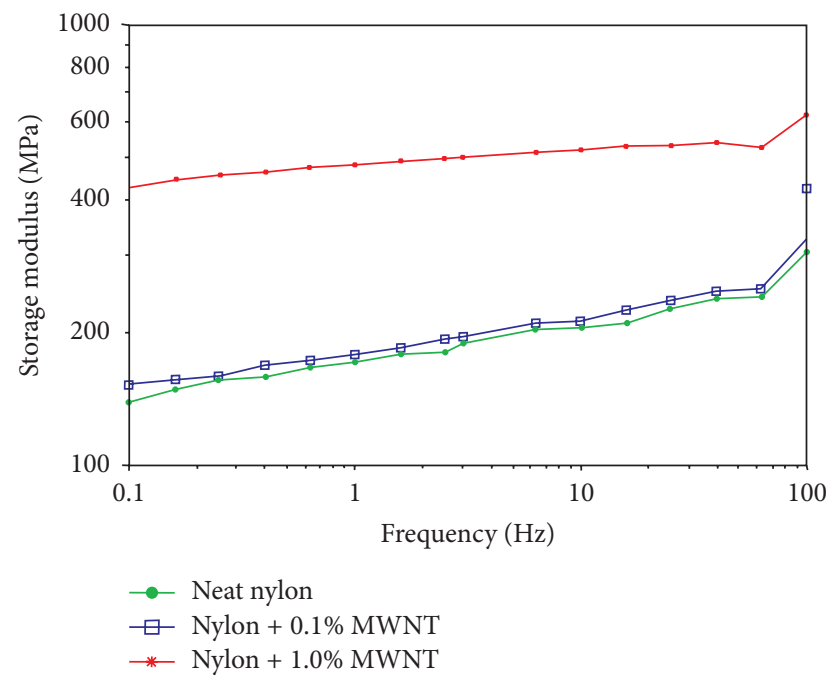

FIGURE 10: Effect of O-MWNT on storage modulus of the nonwoven aligned fibre mat at $6000 \mathrm{rpm}$. Reprinted from [46], Copyright 2011, with permission from Elsevier.

and strength by $\sim 70 \%$ and $\sim 25 \%$, respectively. Dramatic changes on the storage moduli of the electrospun fibres were also observed; at room temperature, the storage modulus of the 7.5 wt.\% O-MWCNTs filled fibres was $250 \%$ higher than the pure PA66 fibres [39]. Storage modulus of PA66 electrospun fibres was enhanced by $118 \%$ for A-MWCNTs nanofibres and $69 \%$ for $\mathrm{AGe}$ based nanofibres at $0.1 \mathrm{wt} . \%$ content of the nanofiller. However when the A-MWCNT loading was increased this property decreased and the opposite behaviour was found for AGe based nanofibres, as seen in Figure 12 [31]. These results were attributed to the tendency of A-MWCNTs to aggregate at higher loadings due to the interaction of the functional groups at the graphitic surface.

RGO and GO are shown to be better reinforcement agents when compared to P-MWCNTs and O-MWCNTs in electrospun PA66 nanofibres [32]. This was attributed to the $2 \mathrm{D}$ nature of graphene which provides a larger surface area compared to the 1D nanotubes, thus favouring the mechanical properties of the nanofibres. GnPs and GO moderately enhanced the mechanical response at low content of these nanofillers; on the other hand, NGO provided increases of $95 \%, 73 \%$, and $82 \%$ in the tensile strength, Young's modulus, and tensile strain, respectively, compared to PA6 nanofibres. The simultaneous increases in these properties were unusual because the usual effect is that one of these properties increases at the expense of another [41]. The strength and stiffness of PA6 nanofibres and nanoyarns were enhanced by the wrapping of RGO onto these structures, showing improvements on the tensile strength of $74 \%$ and $41 \%$ for the nanofibre and nanoyarn nanocomposites, respectively [63].

\section{Applications}

The unique characteristics of electrospun fibres make them candidates for a wide variety of applications. They have been studied in order to develop lightweight, ultra-strong structures for miniaturised and load-bearing applications [35]. Moreover tailoring the nonconducting polymeric matrices with conductive fillers like CNTs and graphene could be used to obtain nanocomposites for sensor applications [54, 75]. Cai et al. developed CNT/LA/PA6 nanofibres for obtaining phase change materials to store and retrieve solar energy [42]. The features obtained in GO/PA6 nanofibres of bimodal fibre diameter promise to have great potential in air/water filter applications [36]. The large surface area and porous nature of carbon based nanofibres offer a very large gas absorptive capacity, making possible greater analyte permeability for sensors [43, 49]. Furthermore these composites could have many advantages such as fast response, longterm stability, high sensitivity, and good reproducibility [43]. Choi et al. also fabricated O-MWCNT/PA66 electrospun fibres for sensing low molecular weight alcohol vapours such as methanol, ethanol, 1-propanol, and 1-butanol [43]. OMWCNT/PA6 nanofibres served as the nanosized backbone for pyrrole electropolymerisation; the obtained nanocomposite was tested for biosensor applications [54]. A similar approach was used by Uzun et al. to electrochemically synthesise a conducting polymer after a graphite electrode was coated with MWCNT/PA6 in order to obtain biosensors for testing glucose containing beverages [93].

Miao et al. have examined a variety of polymers and nanomaterials for their use in electronic devices [8]. These nanofibres have also attracted a lot of attention for fabricating transparent nanocomposites due to the possibility of obtaining fibre diameters smaller than the wavelength of visible light [94]. Furthermore, the incorporation of 1D and 2D carbon structures studied in this review makes the creation of thin, transparent, and electrically conductive materials possible that are required for numerous applications such as liquid crystal displays, light emitting diodes, transistors, actuators, sensors, organic solar cells, and smart textiles [8, 33, 44, $45,76]$. Havel et al. developed thin films of O-MWCNT adsorbed onto PA11 nanofibres in order to obtain a viable candidate to replace ITO, providing sufficient conductivity for most applications, but without the price tag and physical limitations of the current ITO coatings [44]. According to the characteristics found in O-SWCNT/PA6 nanofibres developed by Bak coworkers, these could be applied as transparent electrodes in photoelectronics, such as flexible displays and touch screens, as well as in biological applications, such as actuators [40]. PA66 electrospun fibres were also used as a template to build graphene networks to obtain conductive films while minimising transmittance losses [33]. Ma et al. obtained a patent for producing graphene adsorbed on nanofibres to produce a flexible transparent electrode [57].

Liu and coworkers have provided a review about several electrospun fibres which have found wide applications in biomedical fields [9]. Monty et al. patented a flexible electrode for detecting changes in temperature, humidity, and sodium ion concentration in sweat; this fabric can be made from CNT or graphene adsorbed onto PA electrospun fibres and further functionalised with PPy [74, 75]. CNTs and graphene have been used to reinforce the weak points of existing scaffold materials $[13,18,62]$. Zomer Volpato et al. 


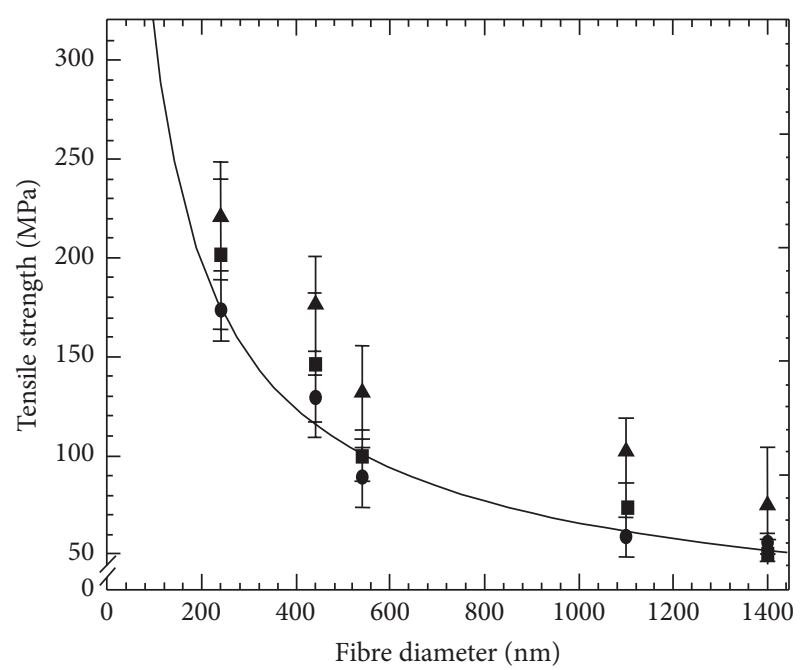

- 0 wt $\%$ CNT

- $1 \mathrm{wt} \% \mathrm{CNT}$
- $2.5 \mathrm{wt} \% \mathrm{CNT}$

- Predicted 0 wt $\%$ CNT

(a)

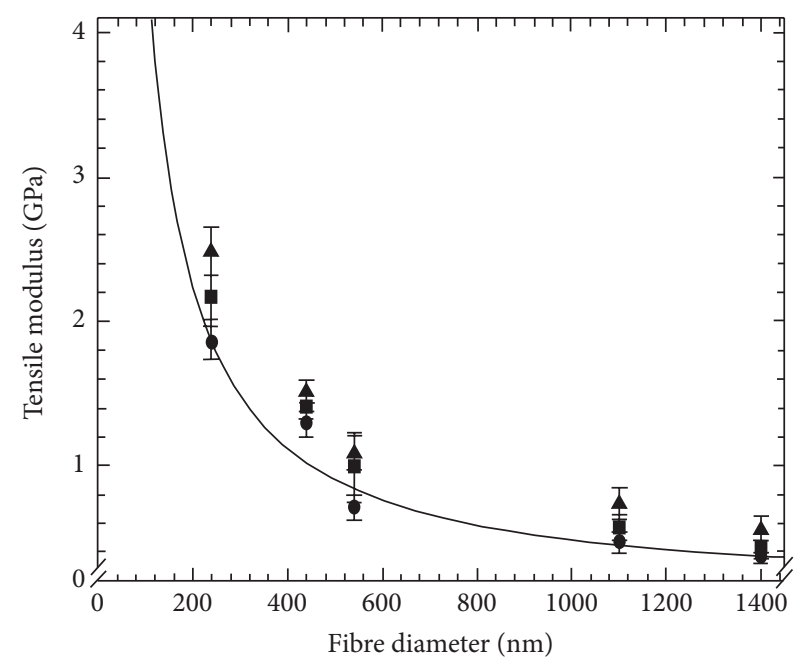

- $0 w \mathrm{wt} \% \mathrm{CNT}$
- $1 \mathrm{wt} \% \mathrm{CNT}$
- $2.5 \mathrm{wt} \% \mathrm{CNT}$ Predicted 0 wt $\%$ CNT

(b)

FIGURE 11: (a) Tensile modulus versus fibre diameter and (b) tensile strength versus fibre diameter. Reprinted from [35], Copyright 2014, with permission from Elsevier.

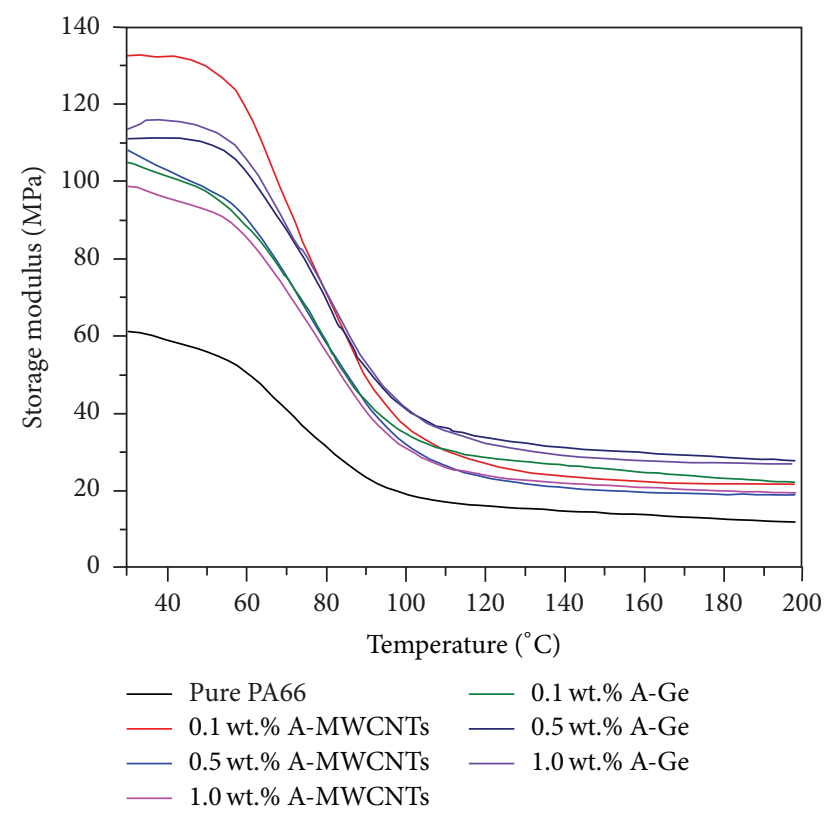

FIGURE 12: Storage modulus of $1 \mathrm{D}$ and $2 \mathrm{D}$ amino reinforced carbon/PA66 electrospun fibres. Published under licence in IOP Conference Series: Materials Science and Engineering by IOP Publishing Ltd.

obtained encouraging results for the use of O-MWCNT/PA6 nanofibres in biomedical applications [53]. In addition, the adjustable morphology and mechanical properties of the electrospun nanofibres are very important in order to mimic specific target tissues that need to be replaced or regenerated $[53,78]$.
Nonwoven nanofibres can be useful for limited applications such as filtration, tissue scaffolds, implant coating films, and wound dressings [36, 71, 80, 86]. On the other hand, continuous single nanofibres or uniaxial fibre bundles provide a wider variety of applications and could improve the performance of the nanofibres [49, 71]. Teo and Ramakrishna have reviewed these nanofibres and classified different levels of organisation in order to construct nanocomposites using electrospun fibres [4]. Another potential application of these nanofibres could be in the reinforcement of other polymers using these nanostructured carbon based electrospun fibres $[58,79,94]$.

In summary, polyamide nanofibres reinforced with carbon nanomaterials qualify for a number of applications such transparent electrodes [40, 57], electronic devices [61, 87], solar cells $[4,50,73]$, drug delivery systems [17, 38], biosensors [54, 62, 93], wearable electronic devices [63, 76, 77], or nanofibrous membranes for filtration $[5,59,80,82,86]$. The promising applications of these nanocomposite fibres have resulted in the publication of patents by several research groups $[57,61]$. It is clear that the study of carbon based/polyamide electrospun will increase the research of these nanocomposites in future.

\section{Conclusion}

This review showed the different investigations of polyamide electrospun nanocomposites using CNTs or graphene as fillers. The selection of an appropriate solvent for the dispersion of carbon nanomaterials is an important factor for solving one of the main issues of carbon based nanocomposites, the dispersion. The other main challenge which is the alignment of nanomaterials is a feature provided by 
electrospinning technique. The diverse studies of polyamide electrospun fibres reinforced with these two novel carbon nanomaterials have showed interesting characteristics for the development of a variety of applications in diverse fields of science and technology. However the potential of this technique in polyamides has not been exploited sufficiently when concerning to the reinforcing of the fibres with CNTs and graphene. More efforts need to be made in understanding the behaviour of these different structures of carbon in polyamide matrices in order to achieve the best dispersion and alignment for obtaining nanocomposites with exceptional properties.

\section{List of Abbreviations}

$\begin{array}{ll}\text { 1D: } & \text { One-dimensional } \\ \text { 2D: } & \text { Two-dimensional } \\ \text { AA: } & \text { Acetic acid } \\ \text { AGe: } & \text { Amino functionalised graphene } \\ \text { A-MWCNTs: } & \begin{array}{l}\text { Amino functionalised multiwall carbon } \\ \text { nanotubes }\end{array} \\ \text { Ac-MWCNTs: } & \text { Acylated multiwall carbon nanotubes } \\ \text { BSA: } & \text { Bovine serum albumin } \\ \text { CNTs: } & \text { Carbon nanotubes } \\ \text { DCM: } & \text { Dichloromethane } \\ \text { DMA: } & \text { Dimethylamine } \\ \text { DMF: } & \text { Dimethylformamide } \\ \text { EDA: } & \text { Ethylenediamine } \\ \text { EDAC: } & \text { 1-Ethyl-3-[3-dimethylaminopropyl] } \\ \text { FA: } & \text { carbodiimide hydrochloride } \\ \text { GnPs: } & \text { Formic acid } \\ \text { GO: } & \text { Graphene nanoplatelets } \\ \text { HFIP: } & \text { Graphene oxide } \\ \text { LA: } & \text { 1,1,1,3,3,3-Hexafluoro-2-propanol } \\ \text { MWCNTs-OH: } & \text { Lauric acid } \\ \text { Hydroxyl functionalised multiwall carbon } \\ \text { NGO: } & \text { nanotubes } \\ \text { O-MWCNTs: } & \text { Nitroxide functionalised graphene oxide } \\ \text { O-SWCNTs: } & \text { Oxidised multiwall carbon nanotubes } \\ \text { P-CNTs: } & \text { Pristine carbon nanotubes } \\ \text { P-MWCNTs: } & \text { Pristine multiwall carbon nanotubes } \\ \text { PA6: } & \text { Polyamide 6 } \\ \text { PA11: } & \text { Polyamide 11 } \\ \text { PA66: } & \text { Polyamide 6,6 } \\ \text { PA610: } & \text { Polyamide 6,10 } \\ \text { PMMA: } & \text { Polymethyl methacrylate } \\ \text { PPy: } & \text { Polypyrrole } \\ \text { PVP: } & \text { Polyvinylpyrrolidone } \\ \text { RGO: } & \text { Reduced graphene oxide } \\ \text { SOCl }: & \text { Thionloride. } \\ & \end{array}$

\section{Competing Interests}

The authors declare that they have no competing interests.

\section{References}

[1] D. H. Reneker and I. Chun, "Nanometre diameter fibres of polymer, produced by electrospinning," Nanotechnology, vol. 7, no. 3, pp. 216-223, 1996.

[2] Z.-M. Huang, Y.-Z. Zhang, M. Kotaki, and S. Ramakrishna, "A review on polymer nanofibers by electrospinning and their applications in nanocomposites," Composites Science and Technology, vol. 63, no. 15, pp. 2223-2253, 2003.

[3] W. E. Teo and S. Ramakrishna, "A review on electrospinning design and nanofibre assemblies," Nanotechnology, vol. 17, no. 14, pp. R89-R106, 2006.

[4] W.-E. Teo and S. Ramakrishna, "Electrospun nanofibers as a platform for multifunctional, hierarchically organized nanocomposite," Composites Science and Technology, vol. 69, no. 11-12, pp. 1804-1817, 2009.

[5] P. Heikkilä, A. Taipale, M. Lehtimäki, and A. Harlin, "Electrospinning of polyamides with different chain compositions for filtration application," Polymer Engineering and Science, vol. 48, no. 6, pp. 1168-1176, 2008.

[6] V. Thavasi, G. Singh, and S. Ramakrishna, "Electrospun nanofibers in energy and environmental applications," Energy and Environmental Science, vol. 1, no. 2, pp. 205-221, 2008.

[7] C. J. Luo, S. D. Stoyanov, E. Stride, E. Pelan, and M. Edirisinghe, "Electrospinning versus fibre production methods: from specifics to technological convergence," Chemical Society Reviews, vol. 41, no. 13, pp. 4708-4735, 2012.

[8] J. Miao, M. Miyauchi, T. J. Simmons, J. S. Dordick, and R. J. Linhardt, "Electrospinning of nanomaterials and applications in electronic components and devices," Journal of Nanoscience and Nanotechnology, vol. 10, no. 9, pp. 5507-5519, 2010.

[9] H. Liu, X. Ding, G. Zhou, P. Li, X. Wei, and Y. Fan, "Electrospinning of nanofibers for tissue engineering applications," Journal of Nanomaterials, vol. 2013, Article ID 495708, 11 pages, 2013.

[10] C.-C. Liao, C.-C. Wang, C.-Y. Chen, and W.-J. Lai, "Stretchinginduced orientation of polyacrylonitrile nanofibers by an electrically rotating viscoelastic jet for improving the mechanical properties," Polymer, vol. 52, no. 10, pp. 2263-2275, 2011.

[11] G. Wang, Z. Tan, X. Liu et al., "Conducting MWNT/poly(vinyl acetate) composite nanofibres by electrospinning," Nanotechnology, vol. 17, no. 23, pp. 5829-5835, 2006.

[12] K. Ketpang and J. S. Park, "Electrospinning PVDF/PPy/ MWCNTs conducting composites," Synthetic Metals, vol. 160, no. 15-16, pp. 1603-1608, 2010.

[13] C. Wan and B. Chen, "Poly(E-caprolactone)/graphene oxide biocomposites: mechanical properties and bioactivity, Biomedical Materials, vol. 6, no. 5, Article ID 055010, 2011.

[14] S. Mazinani, A. Ajji, and C. Dubois, "Morphology, structure and properties of conductive PS/CNT nanocomposite electrospun mat," Polymer, vol. 50, no. 14, pp. 3329-3342, 2009.

[15] S. R. Givens, K. H. Gardner, J. F. Rabolt, and D. B. Chase, "Hightemperature electrospinning of polyethylene microfibers from solution," Macromolecules, vol. 40, no. 3, pp. 608-610, 2007.

[16] A. Espíndola-González, A. L. Martínez-Hernández, F. Fernández-Escobar et al., "Natural-synthetic hybrid polymers developed via electrospinning: the effect of PET in chitosan/ starch system," International Journal of Molecular Sciences, vol. 12, no. 3, pp. 1908-1920, 2011.

[17] T. J. Sill and H. A. von Recum, "Electrospinning: applications in drug delivery and tissue engineering," Biomaterials, vol. 29, no. 13, pp. 1989-2006, 2008. 
[18] H. Haniu, N. Saito, Y. Matsuda et al., "Basic potential of carbon nanotubes in tissue engineering applications," Journal of Nanomaterials, vol. 2012, Article ID 343747, 10 pages, 2012.

[19] R. Nirmala, R. Navamathavan, H.-S. Kang, M. H. El-Newehy, and H. Y. Kim, "Preparation of polyamide-6/chitosan composite nanofibers by a single solvent system via electrospinning for biomedical applications," Colloids and Surfaces B: Biointerfaces, vol. 83, no. 1, pp. 173-178, 2011.

[20] L. Yeo and J. R. Friend, "Electrospinning carbon nanotube polymer composite nanofibers," Journal of Experimental Nanoscience, vol. 1, pp. 177-209, 2006.

[21] A. L. Martínez-Hernández, C. Velasco-Santos, and V. M. Castaño, "Carbon nanotubes composites: processing, grafting and mechanical and thermal properties," Current Nanoscience, vol. 6, no. 1, pp. 12-39, 2010.

[22] R. Verdejo, M. M. Bernal, L. J. Romasanta, and M. A. LopezManchado, “Graphene filled polymer nanocomposites," Journal of Materials Chemistry, vol. 21, no. 10, pp. 3301-3310, 2011.

[23] B. Pant, H. R. Pant, D. R. Pandeya et al., "Characterization and antibacterial properties of Ag NPs loaded nylon-6 nanocomposite prepared by one-step electrospinning process," Colloids and Surfaces A: Physicochemical and Engineering Aspects, vol. 395, pp. 94-99, 2012.

[24] B. W. Ahn and T. J. Kang, "Preparation and characterization of magnetic nanofibers with iron oxide nanoparticles and poly(ethylene terephthalate)," Journal of Applied Polymer Science, vol. 125, no. 2, pp. 1567-1575, 2012.

[25] Y. X. Gan, "Structural assessment of nanocomposites," Micron, vol. 43, no. 7, pp. 782-817, 2012.

[26] Y. Lu, Y. Zhang, G. Zhang, M. Yang, S. Yan, and D. Shen, "Influence of thermal processing on the perfection of crystals in polyamide 66 and polyamide 66/clay nanocomposites," Polymer, vol. 45, no. 26, pp. 8999-9009, 2004.

[27] G.-M. Kim, G. H. Michler, F. Ania, and F. J. B. Calleja, "Temperature dependence of polymorphism in electrospun nanofibres of PA6 and PA6/clay nanocomposite," Polymer, vol. 48, no. 16, pp. 4814-4823, 2007.

[28] G. Nitya, G. T. Nair, U. Mony, K. P. Chennazhi, and S. V. Nair, "In vitro evaluation of electrospun PCL/nanoclay composite scaffold for bone tissue engineering," Journal of Materials Science: Materials in Medicine, vol. 23, no. 7, pp. 1749-1761, 2012.

[29] Z. Spitalsky, D. Tasis, K. Papagelis, and C. Galiotis, "Carbon nanotube-polymer composites: chemistry, processing, mechanical and electrical properties," Progress in Polymer Science, vol. 35, no. 3, pp. 357-401, 2010.

[30] T. Kuilla, S. Bhadra, D. Yao, N. H. Kim, S. Bose, and J. H. Lee, "Recent advances in graphene based polymer composites," Progress in Polymer Science, vol. 35, no. 11, pp. 1350-1375, 2010.

[31] F. Navarro-Pardo, G. Martínez-Barrera, A. L. MartínezHernández et al., "Nylon 6,6 electrospun fibres reinforced by amino functionalised 1D and 2D carbon," IOP Conference Series: Materials Science and Engineering, vol. 40, Article ID 012023, 2012.

[32] F. Navarro-Pardo, G. Martínez-Barrera, A. L. MartínezHernández et al., "Effects on the thermo-mechanical and crystallinity properties of nylon 6,6 electrospun fibres reinforced with one dimensional (1D) and two dimensional (2D) carbon," Materials, vol. 6, no. 8, pp. 3494-3513, 2013.

[33] Y.-L. Huang, A. Baji, H.-W. Tien et al., "Self-assembly of graphene onto electrospun polyamide 66 nanofibers as transparent conductive thin films," Nanotechnology, vol. 22, no. 47, Article ID 475603, 2011.
[34] J.-S. Jeong, S.-J. Park, Y. H. Shin, Y.-J. Jung, P. S. Alegaonkar, and J.-B. Yoo, "Fabrication of carbon nanotube embedded nylon nanofiber bundles by electrospinning," Solid State Phenomena, vol. 124-126, no. 2, pp. 1125-1128, 2007.

[35] A. Baji, Y.-W. Mai, and S.-C. Wong, "Effect of fiber diameter on the deformation behavior of self-assembled carbon nanotube reinforced electrospun polyamide 6,6 fibers," Materials Science and Engineering A, vol. 528, no. 21, pp. 6565-6572, 2011.

[36] H. R. Pant, C. H. Park, L. D. Tijing, A. Amarjargal, D.-H. Lee, and C. S. Kim, "Bimodal fiber diameter distributed graphene oxide/nylon-6 composite nanofibrous mats via electrospinning," Colloids and Surfaces A: Physicochemical and Engineering Aspects, vol. 407, pp. 121-125, 2012.

[37] N. G. Sahoo, H. K. F. Cheng, L. Li, S. H. Chan, Z. Judeh, and J. Zhao, "Specific functionalization of carbon nanotubes for advanced polymer nanocomposites," Advanced Functional Materials, vol. 19, no. 24, pp. 3962-3971, 2009.

[38] T. Kuila, S. Bose, A. K. Mishra, P. Khanra, N. H. Kim, and J. H. Lee, "Chemical functionalization of graphene and its applications," Progress in Materials Science, vol. 57, no. 7, pp. 1061-1105, 2012.

[39] A. Baji, Y.-W. Mai, S.-C. Wong, M. Abtahi, and X. Du, "Mechanical behavior of self-assembled carbon nanotube reinforced nylon 6,6 fibers," Composites Science and Technology, vol. 70, no. 9, pp. 1401-1409, 2010.

[40] H. Bak, S. Y. Cho, Y. S. Yun, and H.-J. Jin, "Electrically conductive transparent films based on nylon 6 membranes and single-walled carbon nanotubes," Current Applied Physics, vol. 10, no. 3, pp. S468-S472, 2010.

[41] Y. I. Avila-Vega, C. C. Leyva-Porras, M. Mireles, M. Quevedo-López, J. Macossay, and J. Bonilla-Cruz, "Nitroxidefunctionalized graphene oxide from graphite oxide," Carbon, vol. 63, pp. 376-389, 2013.

[42] Y. Cai, X. Xu, C. Gao et al., "Effects of carbon nanotubes on morphological structure, thermal and flammability properties of electrospun composite fibers consisting of lauric acid and polyamide 6 as thermal energy storage materials," Fibers and Polymers, vol. 13, no. 7, pp. 837-845, 2012.

[43] J. Choi, E. J. Park, D. W. Park, and S. E. Shim, "MWCNT$\mathrm{OH}$ adsorbed electrospun nylon 6,6 nanofibers chemiresistor and their application in low molecular weight alcohol vapours sensing," Synthetic Metals, vol. 160, no. 23-24, pp. 2664-2669, 2010.

[44] M. Havel, K. Behler, G. Korneva, and Y. Gogotsi, “Transparent thin films of multiwalled carbon nanotubes self-assembled on polyamide 11 nanofibers," Advanced Functional Materials, vol. 18 , no. 16, pp. 2322-2327, 2008.

[45] J. S. Jeong, S. Y. Jeon, T. Y. Lee et al., "Fabrication of MWNTs/nylon conductive composite nanofibers by electrospinning," Diamond and Related Materials, vol. 15, no. 11-12, pp. 1839-1843, 2006.

[46] M. V. Jose, B. W. Steinert, V. Thomas et al., "Morphology and mechanical properties of Nylon 6/MWNT nanofibers," Polymer, vol. 48, no. 4, pp. 1096-1104, 2007.

[47] M. Kang and H.-J. Jin, "Electrospun nanofiber of nylon 610/multi-walled carbon nanotube composites," Key Engineering Materials, vol. 321-323, pp. 934-937, 2006.

[48] H. S. Kim, H.-J. Jin, S. J. Myung, M. Kang, and I.-J. Chin, "Carbon nanotube-adsorbed electrospun nanofibrous membranes of nylon 6," Macromolecular Rapid Communications, vol. 27, no. 2, pp. 146-151, 2006. 
[49] N. L. Lala, V. Thavasi, and S. Ramakrishna, "Preparation of surface adsorbed and impregnated multi-walled carbon nanotube/nylon-6 nanofiber composites and investigation of their gas sensing ability," Sensors, vol. 9, no. 1, pp. 86-101, 2009.

[50] S. Y. Lee, B. Yoo, M. K. Lim, T.-K. Lee, A. R. S. Priya, and K.J. Kim, "Influence of nylon 6 in I3-/I- redox electrolyte on the photovoltaic performance and stability of dye-sensitized solar cells," Langmuir, vol. 26, no. 9, pp. 6638-6642, 2010.

[51] Y. Liu, J. Li, and Z.-J. Pan, "The dispersion of CNT and the conductive property of PA6/MWNTs nanofiber filaments by electrospinning," Advanced Materials Research, vol. 295-297, pp. 1993-1997, 2011.

[52] K. Saeed, S.-Y. Park, S. Haider, and J.-B. Baek, "In situ polymerization of multi-walled carbon nanotube/nylon-6 nanocomposites and their electrospun nanofibers," Nanoscale Research Letters, vol. 4, no. 1, pp. 39-46, 2009.

[53] F. Zomer Volpato, S. L. Fernandes Ramos, A. Motta, and C. Migliaresi, "Physical and in vitro biological evaluation of a PA 6/MWCNT electrospun composite for biomedical applications," Journal of Bioactive and Compatible Polymers, vol. 26, no. 1, pp. 35-47, 2011.

[54] X. Wang, X. Wang, X. Wang et al., "Novel electrochemical biosensor based on functional composite nanofibers for sensitive detection of p53 tumor suppressor gene," Analytica Chimica Acta, vol. 765, pp. 63-69, 2013.

[55] L. Albañil-Sanchez, A. Romo-Uribe, A. Flores, and R. CruzSilva, "Electrospun nylon-graphene nanocomposites synthesis and microstructure," MRS Proceedings, vol. 1453, 8 pages, 2012.

[56] C. Leyva-Porras, C. Ornelas-Gutiérrez, M. Miki-Yoshida, Y. I. Avila-Vega, J. Macossay, and J. Bonilla-Cruz, "EELS analysis of Nylon 6 nanofibers reinforced with nitroxide-functionalized graphene oxide," Carbon, vol. 70, pp. 164-172, 2014.

[57] C.-C. M. Ma, Y.-L. Huang, S.-Y. Yang, and H.-W. Tien, “Transparent electrode with flexibility and method for manufacturing the same," US Patent 0295384, 2013.

[58] B. Li, H. Yuan, and Y. Zhang, "Transparent PMMA-based nanocomposite using electrospun graphene-incorporated PA6 nanofibers as the reinforcement," Composites Science and Technology, vol. 89, pp. 134-141, 2013.

[59] H. R. Pant, B. Pant, P. Pokharel et al., "Photocatalytic $\mathrm{TiO}_{2}$ RGO/nylon-6 spider-wave-like nano-nets via electrospinning and hydrothermal treatment," Journal of Membrane Science, vol. 429, pp. 225-234, 2013.

[60] H. R. Pant, B. Pant, C. H. Park et al., "RGO/Nylon-6 composite mat with unique structural features and electrical properties obtained from electrospinning and hydrothermal process," Fibers and Polymers, vol. 14, no. 6, pp. 970-975, 2013.

[61] Y. J. Yun and D. Kibong Song, "Graphene electronic device and method of fabricating the same," US Patent 0313523, 2013.

[62] Y. J. Yun, W. G. Hong, N.-J. Choi et al., "A 3D scaffold for ultrasensitive reduced graphene oxide gas sensors," Nanoscale, vol. 6, no. 12, pp. 6511-6514, 2014.

[63] Y. J. Yun, W. G. Hong, W.-J. Kim, Y. Jun, and B. H. Kim, “A novel method for applying reduced graphene oxide directly to electronic textiles from yarns to fabrics," Advanced Materials, vol. 25, no. 40, pp. 5701-5705, 2013.

[64] J. Shen, M. Shi, B. Yan et al., "Covalent attaching protein to graphene oxide via diimide-activated amidation," Colloids and Surfaces B: Biointerfaces, vol. 81, no. 2, pp. 434-438, 2010.

[65] T.-W. Chou, L. Gao, E. T. Thostenson, Z. Zhang, and J.-H. Byun, "An assessment of the science and technology of carbon nanotube-based fibers and composites," Composites Science and Technology, vol. 70, no. 1, pp. 1-19, 2010.

[66] K. Yang, M. Gu, Y. Guo, X. Pan, and G. Mu, "Effects of carbon nanotube functionalization on the mechanical and thermal properties of epoxy composites," Carbon, vol. 47, no. 7, pp. 1723$1737,2009$.

[67] G. Mago, C. Velasco-Santos, A. L. Martinez-Hernandez, D. M. Kalyon, and F. T. Tisher, "Effect of functionalization on the crystallization behavior of MWNT-PBT nanocomposites," Materials Research Society Symposium Proceedings, vol. 1056, pp. 295-300, 2008.

[68] Q. Bao, H. Zhang, J.-X. Yang et al., "Graphene-polymer nanofiber membrane for ultrafast photonics," Advanced Functional Materials, vol. 20, no. 5, pp. 782-791, 2010.

[69] M. J. Green, N. Behabtu, M. Pasquali, and W. W. Adams, "Nanotubes as polymers," Polymer, vol. 50, no. 21, pp. 49794997, 2009.

[70] M. B. Bazbouz and G. K. Stylios, "Novel mechanism for spinning continuous twisted composite nanofiber yarns," European Polymer Journal, vol. 44, no. 1, pp. 1-12, 2008.

[71] M. B. Bazbouz and G. K. Stylios, "Alignment and optimization of nylon 6 nanofibers by electrospinning," Journal of Applied Polymer Science, vol. 107, no. 5, pp. 3023-3032, 2007.

[72] M. B. Bazbouz and G. K. Stylios, "The tensile properties of electrospun nylon 6 single nanofibers," Journal of Polymer Science, Part B: Polymer Physics, vol. 48, no. 15, pp. 1719-1731, 2010.

[73] S. Y. Jan, H. S. Park, S. M. Jo et al., "Graphene composite nanofibre and preparation method thereof," 2013 US Patent 8,519,045, December 2010.

[74] C. N. Monty, E. K. Wujcik, and N. J. Blasdel, "Flexible electrode for detecting changes in temperature, humidity and sodium ion concentration in sweat," US Patent 2013/0197319, August 2013.

[75] N. J. Blasdel, E. K. Wujcik, J. E. Carletta, K.-S. Lee, and C. N. Monty, "Fabric nanocomposite resistance temperature detector," IEEE Sensors Journal, vol. 15, no. 1, pp. 300-306, 2015.

[76] R. Cruz-Silva, A. Morelos-Gomez, H.-I. Kim et al., "Superstretchable graphene oxide macroscopic fibers with outstanding knotability fabricated by dry film scrolling," ACS Nano, vol. 8, no. 6, pp. 5959-5967, 2014.

[77] Y.-S. Wang, S.-M. Li, S.-T. Hsiao et al., "Integration of tailored reduced graphene oxide nanosheets and electrospun polyamide-66 nanofabrics for a flexible supercapacitor with high-volume- and high-area-specific capacitance," Carbon, vol. 73, pp. 87-98, 2014.

[78] L. Pan, X. Pei, R. He, Q. Wan, and J. Wang, "Multiwall carbon nanotubes/polycaprolactone composites for bone tissue engineering application," Colloids and Surfaces B: Biointerfaces, vol. 93, pp. 226-234, 2012.

[79] A. Kausar, "Mechanical, thermal, and electrical properties of epoxy matrix composites reinforced with polyamide-graftedMWCNT/poly(azo-pyridine-benzophenone-imide)/ polyaniline nanofibers," International Journal of Polymeric Materials and Polymeric Biomaterials, vol. 63, no. 16, pp. 831-839, 2014.

[80] N. Vitchuli, Q. Shi, J. Nowak et al., "Multifunctional ZnO/Nylon 6 nanofiber mats by an electrospinning-electrospraying hybrid process for use in protective applications," Science and Technology of Advanced Materials, vol. 12, no. 5, Article ID 055004, 2011.

[81] R. Zhang and H. Olin, "Carbon nanomaterials as drug carriers: real time drug release investigation," Materials Science and Engineering C, vol. 32, no. 5, pp. 1247-1252, 2012. 
[82] S. Zhang, W. S. Shim, and J. Kim, "Design of ultra-fine nonwovens via electrospinning of Nylon 6: spinning parameters and filtration efficiency," Materials and Design, vol. 30, no. 9, pp. 3659-3666, 2009.

[83] L. M. Guerrini, M. C. Branciforti, T. Canova, and R. E. S. Bretas, "Electrospinning and characterization of polyamide 66 nanofibers with different molecular weights," Materials Research, vol. 12, no. 2, pp. 181-190, 2009.

[84] X. Wang, B. Ding, G. Sun, M. Wang, and J. Yu, "Electrospinning/netting: a strategy for the fabrication of threedimensional polymer nano-fiber/nets," Progress in Materials Science, vol. 58, no. 8, pp. 1173-1243, 2013.

[85] C. Zhang, Y. Li, W. Wang et al., "A novel two-nozzle electrospinning process for preparing microfiber reinforced $\mathrm{pH}$ sensitive nano-membrane with enhanced mechanical property," European Polymer Journal, vol. 47, no. 12, pp. 2228-2233, 2011.

[86] H. R. Pant, M. P. Bajgai, C. Yi et al., "Effect of successive electrospinning and the strength of hydrogen bond on the morphology of electrospun nylon-6 nanofibers," Colloids and Surfaces A: Physicochemical and Engineering Aspects, vol. 370, no. 1-3, pp. 87-94, 2010.

[87] R. Nirmala, K. S. Jeon, R. Navamathavan, M. Park, H. Y. Kim, and S.-J. Park, "Enhanced electrical properties of electrospun nylon66 nanofibers containing carbon nanotube fillers and $\mathrm{Ag}$ nanoparticles," Fibers and Polymers, vol. 15, no. 5, pp. 918-923, 2014.

[88] S.-Y. Park, Y.-H. Cho, and R. A. Vaia, "Three-dimensional structure of the zone-drawn film of the nylon-6/ layered silicate nanocomposites," Macromolecules, vol. 38, no. 5, pp. 1729-1735, 2005.

[89] N. A. Jones, E. D. T. Atkins, and M. J. Hill, "Investigation of solution-grown, chain-folded lamellar crystals of the even-even nylons: 6 6, 8 6, 8 8, 10 6, 10 8, 1010,12 6, 12 8, 12 10, and 1212 ," Journal of Polymer Science, Part B: Polymer Physics, vol. 38, no. 9, pp. 1209-1221, 2000.

[90] J. S. Stephens, D. B. Chase, and J. F. Rabolt, "Effect of the electrospinning process on polymer crystallization chain conformation in nylon-6 and nylon-12," Macromolecules, vol. 37, no. 3, pp. 877-881, 2004.

[91] C. T. Lim, E. P. S. Tan, and S. Y. Ng, "Effects of crystalline morphology on the tensile properties of electrospun polymer nanofibers," Applied Physics Letters, vol. 92, no. 14, Article ID 141908, 2008.

[92] K. S. Jeon, R. Nirmala, R. Navamathavan, and H. Y. Kim, "Mechanical behavior of electrospun Nylon66 fibers reinforced with pristine and treated multi-walled carbon nanotube fillers," Ceramics International, vol. 39, no. 7, pp. 8199-8206, 2013.

[93] S. D. Uzun, F. Kayaci, T. Uyar, S. Timur, and L. Toppare, "Bioactive surface design based on functional composite electrospun nanofibers for biomolecule immobilization and biosensor applications," ACS Applied Materials \& Interfaces, vol. 6, no. 7, pp. 5235-5243, 2014.

[94] M. M. Bergshoef and G. J. Vancso, "Transparent nanocomposites with ultrathin, electrospun nylon-4,6 fiber reinforcement," Advanced Materials, vol. 11, no. 16, pp. 1362-1365, 1999. 

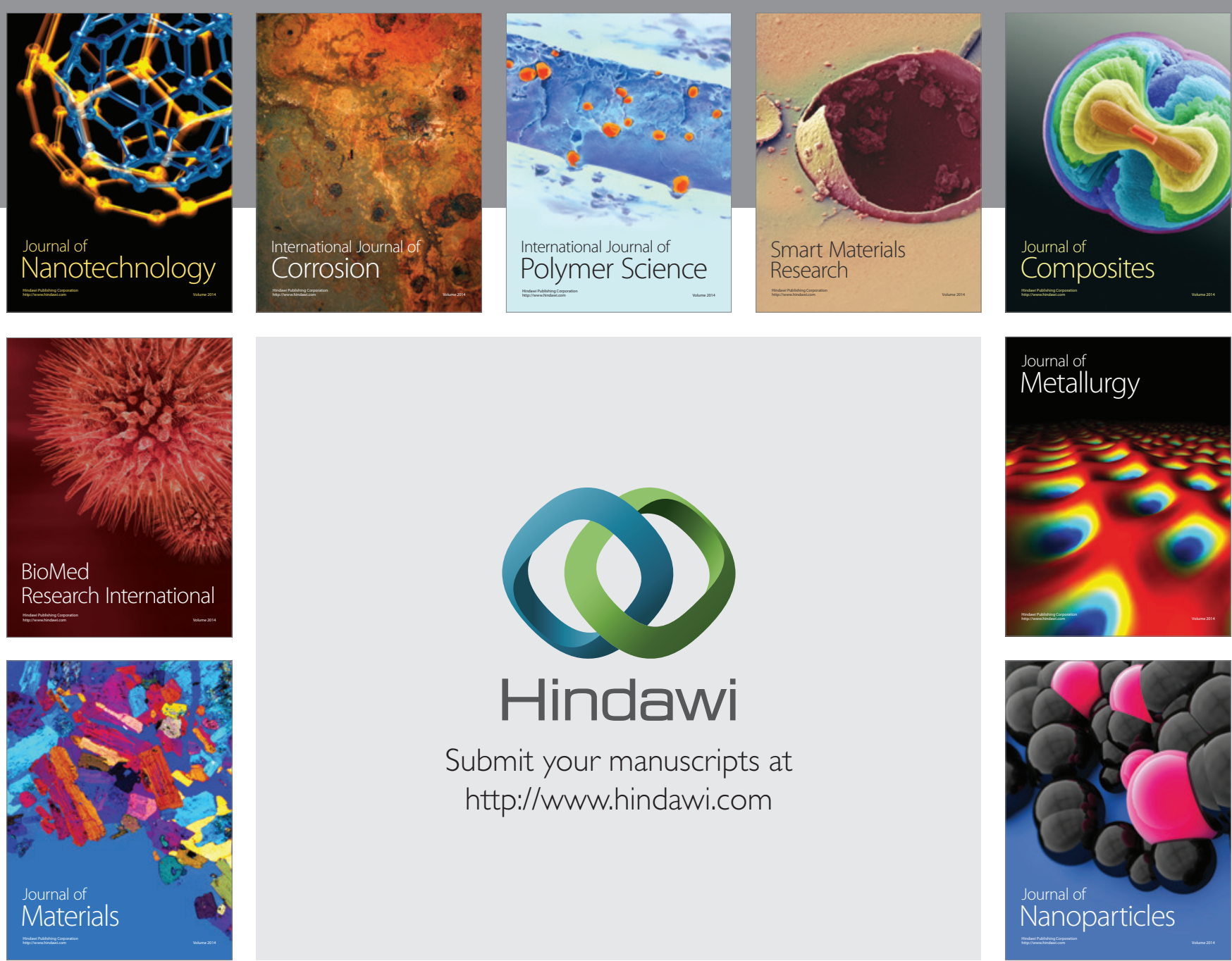

\section{Hindawi}

Submit your manuscripts at

http://www.hindawi.com

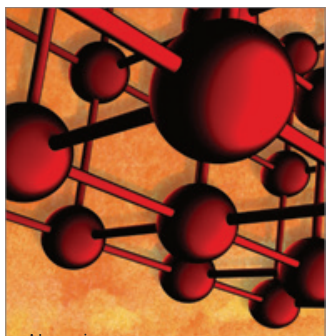

Materials Science and Engineering
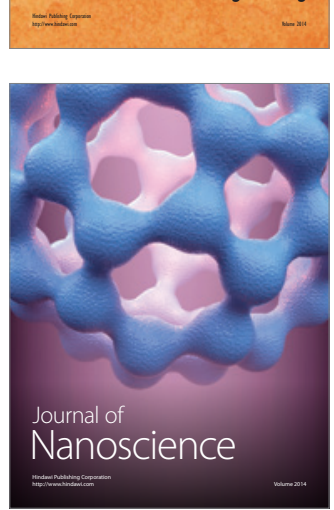
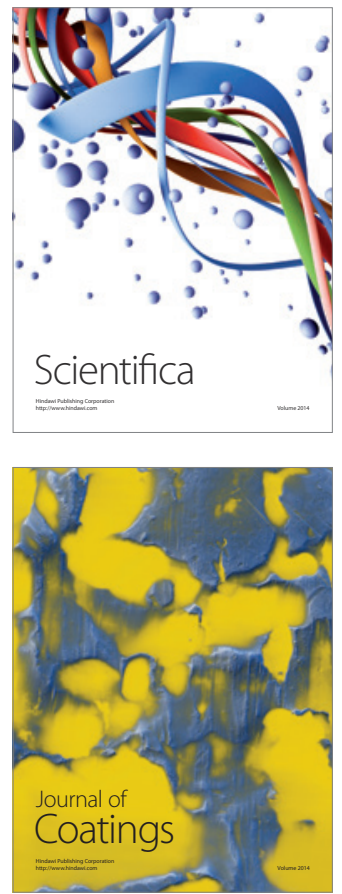
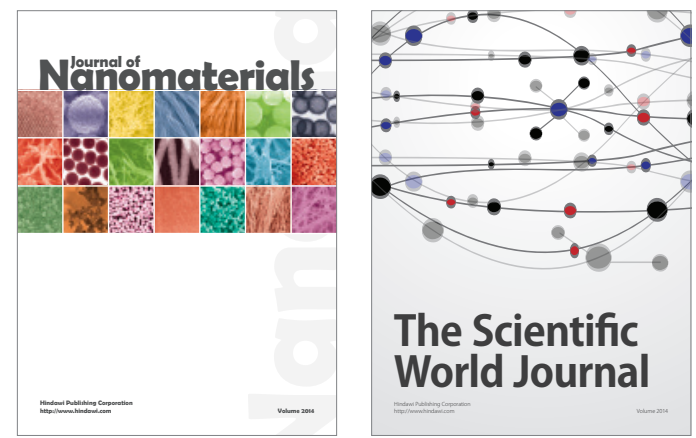

The Scientific World Journal
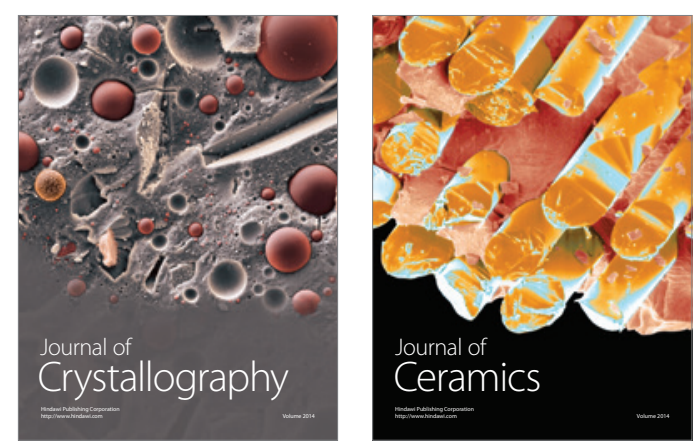
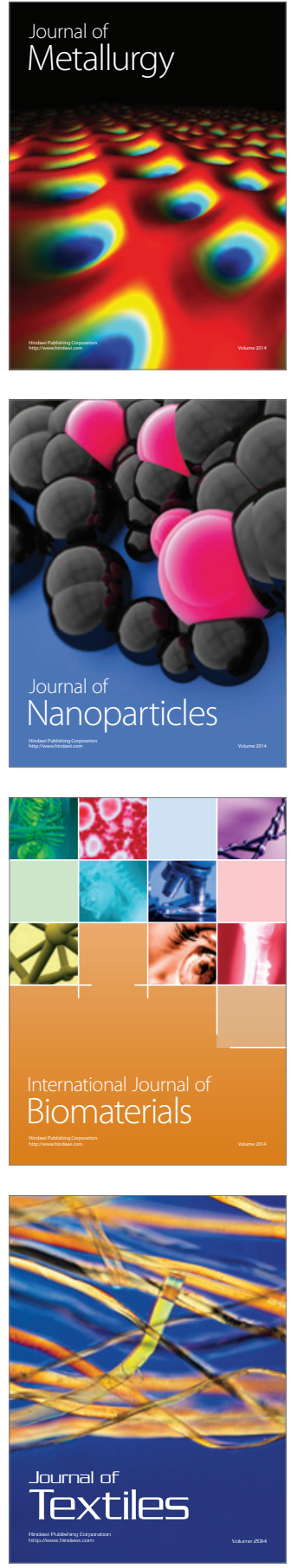